\title{
Oxidative depolymerization of lignins for producing aromatics: variation of botanical origin and extraction methods
}

\author{
Cédric Cabral Almada, Aleksandr Kazachenko, Pascal Fongarland, Denilson Da Silva Perez, Boris N. \\ Kuznetsov, Laurent Djakovitch
}

\begin{abstract}
Several lignin samples of varying botanical nature (softwood, hardwood, or annual plants) and extraction procedures (Kraft, Organosolv, or soda) were fully characterized by complementary techniques and engaged in "catalyst-free" depolymerization in air under basic conditions. Treatment of the complex reaction mixture was optimized to ensure reproducibility, careful analyses, and accurate data. After an optimization of the reaction conditions, we were able to recover high amounts of aromatic compounds (up to 19\%wt). Additionally, we demonstrated a relation between lignin's structure, i.e., the accessible phenol moieties and inter-unit linkages, and the yields of aromatic compounds, thus showing the importance of the extraction process to optimize lignin's potential. This work provides valuable reference for developing further lignin depolymerization under basic media.
\end{abstract}

\section{Introduction}

Lignin valorization became last years a highly attractive area due to its potential for producing chemicals, fuels and bio-based materials, particularly with high content of aromatics ${ }^{1,2}$. Actually, lignin is the second most abundant bio-polymer that did not compete with food industries, after cellulose, representing $c a$. $25 \%$ of available biomass and the only one made of aromatics. Lignins are mainly produced by paper industries (i.e.: Kraft, Sulfite or Soda processes); however, few new biorefineries produce as well so called Organosolv lignins. Lignin is a complex three-dimensional bio-polymer consisting in random polymerization of three main building blocks bearing $p$-hydroxyphenyl $(H)$, guaiacyl (G) and syringyl (S) units. The content of these three main units in lignins and the type of associated inter-units bonds depends mainly on the botanic origin, whereas the structure of the biopolymer depends additionally on lignin extraction methods ${ }^{1,3-7}$. Therefore, developing efficient processes to produce aromatics from lignins remains a major challenge given their variable structures and compositions justifying the intensive researches in this area. Theses researches aim also at enhancing the economical balance of biorefineries by providing alternative valorization of lignins towards higher added value products. 
Several approaches, using or not catalysts, were reported in order to convert lignins into valuable chemicals and were partly reviewed ${ }^{6,8-13}$ : they include, hydrolysis ${ }^{14-20}$, solvolysis ${ }^{2,}{ }^{21-29}$, thermal liquefaction $^{30-36}$, pyrolysis ${ }^{37-41}$, hydrogenolysis ${ }^{42-55}$, hydrogenation ${ }^{43,47,56-60}, \mathrm{HDO}^{61-63}$, oxidation ${ }^{64-69}$ and enzymatic depolymerization ${ }^{18,70-75}$, or even combination of such methodologies ${ }^{76}$. Among, the oxidative depolymerization represents an interesting case as it allows the direct formation of carbonyl derivatives, including benzaldehydes like vanillin and syringaldehyde for which the market is highly developed. Given the complexity of lignins, most of the reports referred to lignin model compounds ${ }^{77-}$ ${ }^{86}$. However, on lignins themselves, several studies were reported using various oxidant $\left(\mathrm{O}_{2}, \mathrm{H}_{2} \mathrm{O}_{2}\right.$, $\left.\mathrm{O}_{3} \ldots\right)^{67,80,87}$ with or not catalysts. Various homogeneous and heterogeneous catalysts were used in catalytic oxidative depolymerization of lignins ${ }^{8,10}$. Organometallic compounds were described for this application. Without being exhaustive, MTO, supported or not on (poly(4-vinylpyridine) or poly(4vinylpyridine- $\mathrm{N}$-oxide)), was reported by Crestini et al. ${ }^{78}$ in studies related to Kraft lignin depolymerization. Authors reports that lignin was effectively oxidized under their conditions as observed from NMR analyses that exhibited decrease in hydroxyl content coupled to increase of carboxylic acid groups. Recently, the group of C. Bolm reported the use of iron based catalysts [FeDABCO] in the presence of $\mathrm{H}_{2} \mathrm{O}_{2}$ and acetic acid in a mixture of $\mathrm{DMSO} / \mathrm{H}_{2} \mathrm{O}$ for depolymerizing commercial Kraft lignin. Spectroscopic and SEC analyses showed a certain degree of depolymerization that was attributed to the degradation of $\beta-0-4$ linkages and resorcinol sub-units ${ }^{88}$. Data indicates that key species facilitating these cleavages are methyl radicals generated from $\mathrm{H}_{2} \mathrm{O}_{2}$ and DMSO. Polyoxometallate (POM) constitute probably another family of common homogeneous catalysts evaluated in depolymerization of lignins. Voitl et al. reported the oxidative depolymerization of Organosolv lignin using $\mathrm{H}_{3} \mathrm{PMO}_{12} \mathrm{O}_{40}$ as catalyst in water/alcohol mixtures at $170^{\circ} \mathrm{C}$ under oxygen (5 bar $)^{89,90}$. Vanillin and methylvanillin were obtained in a total yield of $5 \%$ wt in 20 min. Recently, De Gregorio et al. reported the use of $\mathrm{H}_{5} \mathrm{PV}_{2} \mathrm{Mo}_{10} \mathrm{O}_{40}$ as catalysts in ionic liquid for the depolymerization of lonosolv lignins in the presence of oxygen or $\mathrm{H}_{2} \mathrm{O}_{2}$ as the oxidant ${ }^{91}$. Phenols, including vanillin and syringaldehyde, were observed, however; in relative low total yield. Recently, some of the authors reported the use of $\mathrm{TiO}_{2}$ as catalyst in lignin oxidation with $\mathrm{H}_{2} \mathrm{O}_{2}$ in ionic liquids showing that the concomitant used of $\mathrm{TiO}_{2}$ allowed to enrich oils in phenolic compounds ${ }^{92}$. Metallic salts (i.e.: copper, iron, manganese...) are commonly used in lignin depolymerization toward aromatics ${ }^{8,67}$. Generally, copper showed the best behavior in such applications, probably the reason why Borregaard developed a process for converting sulfite lignin to vanillin with copper based catalysts in basic media ${ }^{87,93,94}$. Authors reported yield in vanillin up to $8 \%_{w t}$; however, they demonstrated that yields are closely related to the origin of lignin as well as the reaction conditions ${ }^{95}$. To note, after purification yields dropped below $1 \%_{w t}$. Recently, Sagues et al. reported the use of Fenton's reagent for selectively depolymerizing lignin from sweet sorghum bagasse in supercritical ethanol under nitrogen atmosphere 
to produce phenolic oil with a maximum yield of $75 \%_{\mathrm{wt}}$ containing $a .20 \%_{\mathrm{wt}}$ monomeric phenols $\mathrm{s}^{96}$. Alternative approaches consisted in oxidizing smoothly lignin using, for example TEMPO, in order to obtain a more reliable biopolymer for producing aromatic compounds by treatment with formic acid. This methodology was reported by Rahimi and co-workers ${ }^{97,98}$. Alternative approaches consisted in reacting produced aromatic aldehydes with diols to form acetals in order to prevent their over oxidation ${ }^{99}$. Next to homogeneous systems, several heterogeneous catalysts were employed. Few reports concerned immobilization of homogeneous catalysts $66,78,79,100-102$, but most of the current developments involved metal oxides or supported metals. In this area, Perovskites of general formulae $\mathrm{LaCO}_{1-\mathrm{x}} \mathrm{Cu}_{\mathrm{x}} \mathrm{O}_{3}$ (with $\mathrm{x}=0$ 0-0.2) have been prepared and used for depolymerizing cornstalk lignins ${ }^{103-105}$. Authors demonstrated that the Perovskite with higher oxygen vacancy (i.e.: $\mathrm{LaCO}_{0,8} \mathrm{Cu}_{0,2} \mathrm{O}_{3}$ ) produced the highest yields in vanillin $(5,3 \% \mathrm{wt})$, syringaldehyde $(12,8 \% \mathrm{wt})$ and $p$-hydroxybenzaldehyde $(2,9 \% \mathrm{wt})$. Supported Pt and Pd particles on $\gamma-\mathrm{Al}_{2} \mathrm{O}_{3}$ were used separately by the groups of Sales ${ }^{106,107}$ and Villar ${ }^{108}$ showing that generally in the presence of catalysts the yields in vanillin, syringaldehyde and $p$ hydroxybenzaldehyde increased that was associated to a decreased in recovered lignin. Recently Wang and co-workers reported that $\mathrm{Pd} / \mathrm{CeO}_{2}$ catalysts was able to catalyze Organosolv lignin depolymerization to produce vanillin $\left(5.2 \%_{\mathrm{wt}}\right)$, guaiacol $\left(0.8 \%_{\mathrm{wt}}\right)$ and $\mathrm{p}$-hydroxybenzaldehyde $\left(2.4 \%_{\mathrm{wt}}\right)$ under oxygen. Nevertheless, in this area $\mathrm{CuO}$ based catalysts retained particular attention as they exhibited high activity. However, Villar group showed that in the presence of catalysts yields in aromatic compounds decreased due to over oxidation in batch reactor ${ }^{108}$ that seems to be supported by recent report from Watanabe group in a work related to production of vanillin, synringaldehyde and vanillic acid from wood using $\mathrm{CuO} / \mathrm{H}_{2} \mathrm{O}_{2}$ under microwave heating ${ }^{109}$. In this work authors obtained up to $11.4 \%_{\mathrm{wt}}$ total yield in aromatic compounds that was mainly attributed to the relative short reaction time used $(20 \mathrm{~min})$ at relative high temperature $\left(200^{\circ} \mathrm{C}\right)$. While catalytic methodologies seem to provide interesting results, few reports concerned non catalytic oxidative depolymerization of lignin. Generally reactions were conducted under highly basic conditions (i.e. $\mathrm{pH}=13-14$ ) at temperature above $100^{\circ} \mathrm{C}^{77,80,83,87,106,110-119}$. Commonly, yields increased with increasing base concentration. The nature of lignin played also a main role. Tarabanko studied the mechanism of such depolymerization and reported that vanillin was produced from lignin via oxidation after deprotonation of phenolic moieties by the base ${ }^{76,120}$. While apparently less effective, this approach offers interesting alternatives to the use of catalysts for producing aromatic compounds, approach potentially implementable in biorefineries like paper industries where lignin is one of the main components of highly basic black liquors.

With such an idea in mind, we investigated lignin depolymerization under basic conditions via an oxidative route using oxygen of air as the oxidant. To be in the nearest conditions of paper industries, 
we decided to use exclusively water as the solvent avoiding addition of co-solvents that can therefore impact the eventual implementation of the results such biorefineries without deep adaptation of the processes.

\section{Experimental}

\section{Methods}

$\mathrm{C}, \mathrm{H}, \mathrm{O}, \mathrm{N}$ and $\mathrm{S}$ content measurements of initial lignins were done by SCA-ISA. Oxygen was measured after pyrolysis and quantification of $\mathrm{CO}$ by a specific IR detector. Carbon, hydrogen, nitrogen and sulfur were measured after total combustion of the sample and quantification of $\mathrm{CO}_{2}, \mathrm{H}_{2} \mathrm{O}, \mathrm{N}_{2}$ and $\mathrm{SO}_{2}$ by a thermal conductivity detector.

Lignins were thermally characterized by TGA with TGA/DSC 1 thermogravimetric analyzer from METTLER TOLEDO. The samples were analyzed as received using a heating rate of $5{ }^{\circ} \mathrm{C} / \mathrm{min}$ from $25^{\circ} \mathrm{C}$ to $1000{ }^{\circ} \mathrm{C}$. Air was used as carrier gas. The water content corresponds to the weight loss at $100{ }^{\circ} \mathrm{C}$ whereas the remaining weight at $1000^{\circ} \mathrm{C}$ corresponds to the ash content.

FT-IR analyses were carried out in a transmission mode using a Vector 22 apparatus on lignin and lignin residues in order to get structural information. A mixing $2 \mathrm{mg}$ of sample in $400 \mathrm{mg}$ of $\mathrm{KBr}$ was made and pressed by a 2 tons pressure to form pellets. The range of data acquisition ran from 400 to 4000 $\mathrm{cm}^{-1}$ with a $0.96 \mathrm{~cm}^{-1}$ step.

NMR spectra were acquired on a Bruker AVANCE III 400MHz equipped with a BBFO probe (Z gradient). All chemical shifts were measured relatively to the deuterated solvents in case of ${ }^{13} \mathrm{C} \mathrm{NMR} \mathrm{(in} \mathrm{CDCl}_{3}: \delta$ $=77.0 \mathrm{ppm},\left(\mathrm{CD}_{3}\right)_{2} \mathrm{SO}: \delta=39.7 \mathrm{ppm}$ ), or to the residual protic solvent for ${ }^{1} \mathrm{H} \mathrm{NMR}$ (in $\mathrm{CDCl}_{3}: \delta=7.26$ $\left.\mathrm{ppm},\left(\mathrm{CD}_{3}\right)_{2} \mathrm{SO}: \delta=2.50 \mathrm{ppm}\right)$. Regarding ${ }^{31} \mathrm{P} \mathrm{NMR}$, the chemical shifts were measured relatively to the product of the reaction of TMDP with water in pyridine- $\mathrm{CDCl}_{3}$ solvent $(\delta=132.2 \mathrm{ppm})$. Data are reported as follows: chemical shift, multiplicity $(s=$ singlet, $d=$ doublet, $t=$ triplet, $q=$ quartet, $m=$ multiplet) and coupling constants $(\mathrm{J}$ in $\mathrm{Hz})$, integration and assignments in that order. For ${ }^{1} \mathrm{H} N M R$ analysis, around $8 \mathrm{mg}$ of sample were dissolved in $0.6 \mathrm{~mL}$ of a solution containing TKS (Concentration: $\left.0.04 \mathrm{mg} / \mathrm{g}_{\text {solution }}\right)$ in DMSO-d $\mathrm{d}^{6}$. For ${ }^{13} \mathrm{C}$ and HSQC NMR analyses, $50 \mathrm{mg}$ of sample were weighted and dissolved in $600 \mathrm{mg}$ of $\mathrm{DMSO}-\mathrm{d}^{6}$. For ${ }^{13} \mathrm{C}$ experiments, $0.1 \mathrm{~mL}$ of a solution containing tetramethylthiourea $\left(40 \mathrm{mg} / \mathrm{g}_{\text {solution }}\right)$ and $\mathrm{Fe}(\mathrm{acac})_{3}\left(4 \mathrm{mg} / \mathrm{g}_{\text {solution }} /\right.$ relaxing agent) were added to the sample. All the acquisitions were done at $50{ }^{\circ} \mathrm{C}$ for at least one night (13C: 11000 scans; HSQC: 48 scans). The characterization and quantification of hydroxyl groups in lignin were made using previously developed methods. In these techniques, phosphytilation is carried out before NMR analysis. TMDP 
was used as reagent enabling quantification of different $\mathrm{OH}$ groups (phenol, aliphatic, carboxylic). Samples were accurately weighted (c.a. $30 \mathrm{mg}$ ) and dissolved in $0.5 \mathrm{~mL}$ of a solution of cyclohexanol $\left(3.95 \mathrm{mg} / \mathrm{g}_{\text {solution }}\right)$ in a combination of pyridine and DMF ( $\left./ \mathrm{v}: 1 / 1\right)$. Then $200 \mathrm{mg}$ of $\mathrm{CDCl}_{3}$ and $100 \mathrm{mg}$ of TMDP were added.

GC analyses were performed on a Shimadzu GC-2010 chromatograph equipped with a FID detector, a AOC-20i+ autosampler and a Phenomenex Zebron ZB-5HT column (cross-linked of $5 \%$ Phenyl - $95 \%$ dimethylpolysiloxane, $30 \mathrm{~m} \times 0.25 \mathrm{~mm} \times 0.25 \mu \mathrm{m}$ ). Nitrogen was used as carrier gas (Conditions: $60^{\circ} \mathrm{C}$ for $2 \mathrm{Min} /$ Heat up to $150{ }^{\circ} \mathrm{C}$ (rate $30^{\circ} \mathrm{C} / \mathrm{min}$ ) / Heat up to $200^{\circ} \mathrm{C}$ (rate $2^{\circ} \mathrm{C} / \mathrm{min}$ ) / Heat up to $300^{\circ} \mathrm{C}$ (rate $10^{\circ} \mathrm{C} / \mathrm{min}$ ) / $300^{\circ} \mathrm{C}$ for $2 \mathrm{Min}$ ). The mass spectra were obtained on a Shimadzu GC-MS-QP2010S equipped with a AOC-20i+ autosampler and a Sulpelco SLB-5MS column (5\% Phenyl - $95 \%$ dimethylpolysiloxane, $30 \mathrm{~m} \times 0.25 \mathrm{~mm} \times 0.25 \mu \mathrm{m}$ ). Helium was used as carrier gas. The GC conditions applied are those used for the GC-FID. LC-MS analysis was conducted on a Shimadzu LCMS-2020. A Luna Phenyl-hexyl, $3 \mu \mathrm{m}, 100 \mathrm{~A}, 250 \times 2.5 \mathrm{~mm}$ column. The mobile phase is made of: water (A), acetonitrile (B) and methanol (C). Solvent $C$ is maintained at $10 \%$. Solvent $B$ was maintained for 30 min at $5 \%$, then increased at $30 \%$ for $25 \mathrm{~min}, 80 \%$ for $30 \mathrm{~min}$ and finally kept at $80 \%$ for $20 \mathrm{~min}$. Then the solvent $B$ is set at $5 \%$ to prepare the next analysis. The flow rate is set at $0.5 \mathrm{~mL} / \mathrm{min}$.

\section{Kraft lignin}

The highly alkaline black liquor was neutralized with $\mathrm{CO}_{2}$ by bubbling to precipitate lignin. After centrifugation, the recovered solid has a purity of $60 \%$. It was washed by dispersing it in a $2 \%{ }_{w t} \mathrm{H}_{2} \mathrm{SO}_{4}$ followed by centrifugation. After three purification cycles and drying, a purity of $92 \%$ was achieved.

\section{Ethanol SEL and PEL-Lignin}

Air dry wood (moisture content $5.8 \%$ wt) was milled to fraction $<0.5 \mathrm{~mm}$. A suspension of $100 \mathrm{~g}$ of wood in $1000 \mathrm{ml}$ of solvent (60\%wt of ethanol $+40 \%_{w t}$ of water) was loaded into a stainless steel cylindrical autoclave of $2000 \mathrm{ml}$ capacity. The autoclave was closed and flushed with argon to remove air. The autoclave was heated at $190^{\circ} \mathrm{C}$ for Aspen wood and $200^{\circ} \mathrm{C}$ for Abies wood during 3 hours, and after that it was cooled up to $40^{\circ} \mathrm{C}$. Then the products were filtrated with isolation of the "organosolv liquor" and the solid residue. The solid residue was extensively washed at room temperature with water and ethanol-water mixture (60\%wt of ethanol $+40 \%$ wt of water). The filtrate ("organosolv liquor") and the washing solution were combined. Finally, the dissolved lignin was separated from the combined liquor by precipitation upon dilution with water at $4^{\circ} \mathrm{C}\left(3: 1 \mathrm{v} / \mathrm{v}\right.$ dilution ratio $\mathrm{H}_{2} \mathrm{O}$ : "organosolv liquor") during 12 hours. After filtration with a Buchner funnel, the lignin was extensively washed with distilled water, dried at $50^{\circ} \mathrm{C}$ in a vacuum oven, and weighed to determine the yields of 
lignin that was, for Aspen (PEL) and Abies (SEL) wood were, respectively $10 \%_{w t}$ and $7 \%_{w t}$ related to the wood engaged. Purity of these lignins reached $98 \%$ and $93 \%$, respectively.

\section{Typical experiment}

Depolymerization experiments under oxidative conditions were carried out in a $300 \mathrm{~mL}$ batch reactor equipped with $260 \mathrm{~mL}$ air ballast. Pressure transmitters (Keller PR33 with a converter Keller K-104) are used either to follow the pressure in the reactor and the oxygen consumption in the ballast.

$150 \mathrm{~mL}$ solution of lignin and sodium hydroxide was prepared and introduced into the reactor. The reactor was closed and flushed 3 times with Ar. Stirring rate was fixed to $1500 \mathrm{rpm}$ and the reactor was heated up to the desired temperature. As soon as the reaction temperature was reached, Air was added at the desired pressure (time $=0 \mathrm{~h}$ ). The ballast was opened to maintain constant pressure inside the reactor during all the experiment. After a given period of time, the experiment was stopped by cooling the reactor with an ice bath. Before opening the reactor, gases were collected in $1 \mathrm{~L}$ tedlar bag and analyzed by GC-TCD.

$50 \mathrm{~mL}$ of the reaction mixture was sampled and a solution of $\mathrm{HCl}(10 \%)$ was added until $\mathrm{pH}=1$ to precipitate non liquefied part of lignin. The resulting precipitate was separated by centrifugation for 10 min at 4000rpm and washed twice with a solution of $\mathrm{HCl}(10 \%)$ before being dried under vacuum giving a so-called "precipitated" fraction. The supernatant solution was extracted with DCM $(100 \mathrm{~mL} x$ 3 ) to recover the aromatics ("DCM" fraction). The remaining aqueous phase was dried under vacuum and the residue was taken-up with THF to remove salts ("THF" fraction).

\section{Results and discussions}

\section{Characterization of lignins}

Five lignins, a Kraft lignin, a soda lignin and three Organosolv lignins were engaged in the study. The Kraft lignin was isolated from a Pinus Pinaster black liquor issued form Paper industry by precipitation through $\mathrm{CO}_{2}$ bubbling before being wash by dilute $\mathrm{H}_{2} \mathrm{SO}_{4}$ aqueous solution and was provided by FCBA $^{121}$. The commercially available Protobind ${ }^{\mathrm{TM}}$ P1000 lignin was produced by ALM India. It was extracted from wheat straw by a soda process. An Organosolv Formic lignin was produced from wheat straw by extraction using a mixture of formic acid and acetic acid following the CIMV process, and the two other Organosolv lignins were produced by ethanol extraction from Aspen (PEL) and Abies (SEL) woods following the original procedure described separately by Wildschut et $a l$. and Quesada-Medina et $a l .{ }^{122,123}$.

Elemental analyses 
All lignins were characterized through analytical and complementary spectroscopic techniques before their use in oxidative depolymerization. Elemental analysis provided information on the elemental composition and allowed to propose an empirical formula expressed as C9-unit reflecting the original carbon skeleton of the three composing mono-lignols (Table 1). Except the Kraft lignin that contain some sulfur due to the original process, all lignins are "sulfur-free". As expected from the production process, Organosolv lignins, particularly the ethanol lignins, exhibit higher Carbon and Hydrogen content due to condensation of ethanol moieties in the biopolymer either as ether or esters.

Table 1: elemental analyses of initial lignins.

\begin{tabular}{cccccccc}
\hline & $\mathbf{C}$ & $\mathbf{H}$ & $\mathbf{O}$ & $\mathbf{N}$ & $\mathbf{S}$ & $\begin{array}{c}\text { Empirical } \\
\text { Formula }\end{array}$ & $\begin{array}{c}\text { Molar mass } \\
\text { (g/mol) }\end{array}$ \\
\hline $\begin{array}{c}\text { Kraft } \\
\text { Organosolv }\end{array}$ & 62.5 & 5.3 & 29.1 & 0.1 & 2.1 & $\mathrm{C}_{9} \mathrm{H}_{9.1} \mathrm{O}_{3.1} \mathrm{~N}_{0} \mathrm{~S}_{0.1}$ & 171.36 \\
$\begin{array}{c}\text { SEL } \\
\text { Organosolv }\end{array}$ & 66.2 & 6.4 & 26.5 & 0.2 & 0.1 & $\mathrm{C}_{9} \mathrm{H}_{10.3} \mathrm{O}_{2.7} \mathrm{~N}_{0} \mathrm{~S}_{0}$ & 161.57 \\
$\begin{array}{c}\text { PEL } \\
\text { P1000 }\end{array}$ & 63.0 & 6.5 & 30.0 & 0.1 & 0.1 & $\mathrm{C}_{9} \mathrm{H}_{11} \mathrm{O}_{3.2} \mathrm{~N}_{0} \mathrm{~S}_{0}$ & 171.15 \\
$\begin{array}{c}\text { Organosolv } \\
\text { Formic }\end{array}$ & 59.9 & 5.6 & 29.5 & 0.6 & 0.9 & $\mathrm{C}_{9} \mathrm{H}_{9.7} \mathrm{O}_{3.2} \mathrm{~N}_{0.1} \mathrm{~S}_{0}$ & 172.12 \\
\hline
\end{tabular}

\section{Thermogravimetric analyses}

TGA analysis delivered additional bulk characteristics of initial lignins (Figure 1). All lignins exhibited desiccation level between 96-98\%; except the Organosolv SEL lignin that showed high ash content (i.e. $6.1 \%)$, other lignin showed ash content in a range of $0.5-3.1 \%$ in good agreement with values generally reported for these materials. 


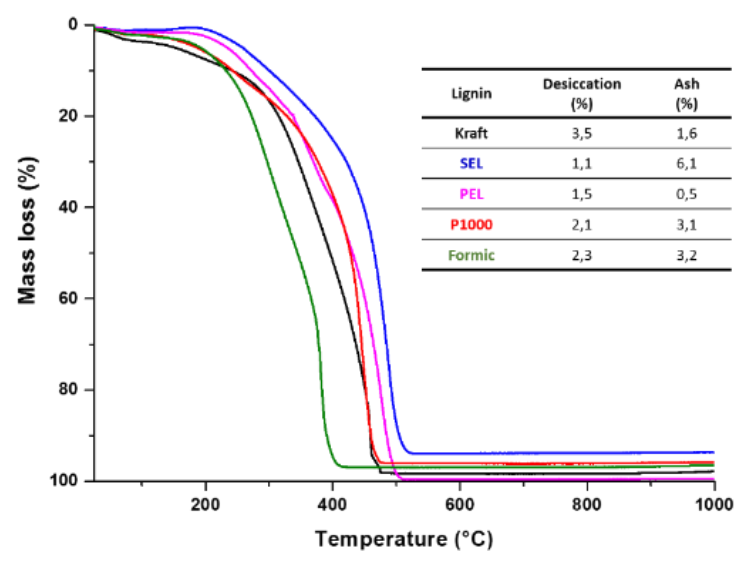

Figure 1: TGA of initial lignins.

\section{FT-IR spectroscopy}

Further characterizations were reached by spectroscopic analyses. All spectra were recorded from $\mathrm{KBr}$ pellets containing $0.5 \%$ wt lignin; spectra were recorded three times for accuracy. IR spectra of initial lignin are depicted in Figure $\mathbf{2} \mathbf{a}$ and $\mathbf{2} \mathbf{b}$, Table $\mathbf{2}$ shows bond assignments.
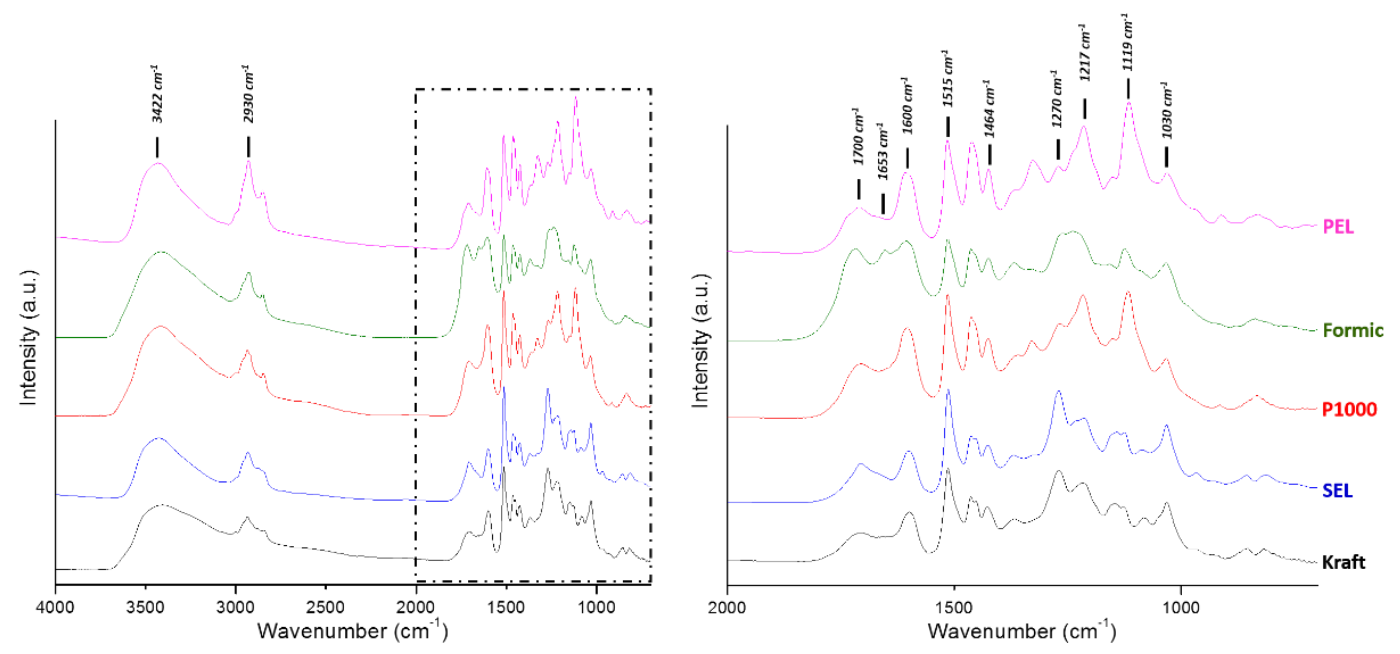

Figure 2: FT-IR spectra of initial lignins (2a) exhibiting the main bands $(2 b)^{124-128}$.

Table2: FT-IR spectra band assignments for initial lignins

\begin{tabular}{cc}
\hline Band $\left(\mathbf{c m}^{-1}\right)$ & Attribution \\
\hline $3412-3460$ & $v \mathrm{OH}$ (alcohol and phenol) \\
$3000-2842$ & $v \mathrm{C}-\mathrm{H}$ aliphatic $\left(-\mathrm{CH}_{3}\right.$ and $\left.-\mathrm{CH}_{2}\right)$ \\
$1738-1709$ & $v \mathrm{C}=\mathrm{O}$ non-conjugated $(\beta$-position and $\mathrm{COOH})$ \\
$1675-1655$ & $v \mathrm{C}=\mathrm{O}$ conjugated $p$-substituted $($ Quinone $)$ \\
$1593-1605$ & $\delta$ aromatic skeleton $; \mathrm{C}=\mathrm{O}$ \\
$1505-1515$ & $v \mathrm{Csp}{ }^{2}=$ Csp ${ }^{2}$ aromatic skeleton
\end{tabular}


$1460-1470$

$1422-1430$

$1365-1370$

$1325-1330$

$1266-1270$

$1221-1230$

1166

1140

$1118-1128$

1086

1030-1035

966-990

915-832 $\delta_{\text {asym. }} \mathrm{C}-\mathrm{H}\left(-\mathrm{CH}_{3}\right.$ et $\left.-\mathrm{CH}_{2}-\right)$

Aromatic skeletal vibrations, $\delta \mathrm{C}-\mathrm{H}$ (in plane)

$v \mathrm{C}-\mathrm{H}$ aliphatic and phenolic $\mathrm{OH}$

$S$ and $G$ condensed units (liaison via la position 5)

$$
v C-O, G \text { unit }
$$

$v \mathrm{C}-\mathrm{C}, v \mathrm{C}-\mathrm{O}$ et $v \mathrm{C}=\mathrm{O}$ (G units)

$\mathrm{C}=\mathrm{O}$ conjugated esters (HGS lignin)

$\delta \mathrm{C}-\mathrm{H}$ aromatic (in plane, $\mathrm{G}$ units)

$v \mathrm{C}-\mathrm{O}$ secondary alcohols and $v \mathrm{C}=\mathrm{O}$ ( $\mathrm{S}$ units)

$\delta \mathrm{C}-\mathrm{O}$ secondary alcohols and aliphatic ethers

$\delta \mathrm{C}-\mathrm{H}$ (G units), $\delta \mathrm{C}-\mathrm{O}$ primary alcohols and $\delta \mathrm{C}=\mathrm{O}$ (non-conjugated)

$\delta-\mathrm{HC}=\mathrm{CH}-$ (out of plane/trans)

$\delta \mathrm{C}-\mathrm{H}$ aromatic skeletal deformation (out of plane)

Among these bands, few are characteristic of lignin structure and can be used to provide semiquantitative information related to lignin transformation during experiments. The bands at $1505 \mathrm{~cm}^{-1}$ and $1515 \mathrm{~cm}^{-1}$ are generally considered as "pure" bands characteristic of aromatic skeleton in lignin biopolymer, generally with high intensity when considering lignin with high $\mathrm{G}$ unit content (i.e. Kraft and SEL) together with the band at $1270 \mathrm{~cm}^{-1}$. Remarkable are also the bands at $1118 \mathrm{~cm}^{-1}$ and 1329 $\mathrm{cm}^{-1}$ characteristic of syringyl units (i.e. PEL and P1000), $1032 \mathrm{~cm}^{-1}$ characteristic of primary alcohols and esters, and the bands at $1655-1675 \mathrm{~cm}^{-1}$ characteristic of quinone units as in the Formic lignin.

\section{NMR analyses}

Most accurate characterization of initial lignins came from NMR studies ${ }^{129-131} .{ }^{1} \mathrm{H},{ }^{13} \mathrm{C},{ }^{31} \mathrm{P}$ and $\mathrm{HSQC}$ (including QQ-HSCQ variant) were used. Despite signal broadening due to polymeric character of lignins, ${ }^{1} \mathrm{H}$ NMR stay a powerful tool to deliver structural information with quantitative data using TKS as internal standard $(\delta=0.202 \mathrm{ppm}){ }^{132,133}$. Figure 3 shows a typical ${ }^{1} \mathrm{H}$ spectra of Kraft lignin (see Supporting Information for ${ }^{1} \mathrm{H}$ NMR spectra of other lignins). Quantitative data are summarized in Table 3. Data indicate, as expected that Organosolv SEL, PEL and Formic lignins exhibit higher concentration in aliphatic proton (i.e. ca 11-13.5 $\mathrm{U}_{\mathrm{H}}$ versus $8.5 \mathrm{U}_{\mathrm{H}}$ ) mainly due to formation of ether and esters, as previously observed from elemental analyses. All lignin exhibit high content in oxygenated aliphatic proton, mainly related to the methoxy groups omnipresent in these biopolymers; however, Organosolv SEL, PEL and Formic lignin showed slightly higher value for these specific functional groups supporting thus ether/ester bond formation during extraction process. Finally, Kraft, SEL and PEL lignin 
exhibit higher content in aromatic proton (i.e. ca 10.6-14.1 $\mathrm{U}_{\mathrm{H}}$ versus 7.9-8.9 $\mathrm{U}_{\mathrm{H}}$ ) probably due to the use of woods to produce these lignins whereas P1000 and Formic lignin came from annual plants (i.e. wheat straw). Noticeably, ${ }^{1} \mathrm{H}$ NMR deliver in simple experiment accurate data regarding $\mathrm{H}$ content together with structural information as almost all hydrogen could be analyzed by this technique given close correlation with the $\mathrm{H}$ content obtained from elemental analysis (except for P1000 lignin).

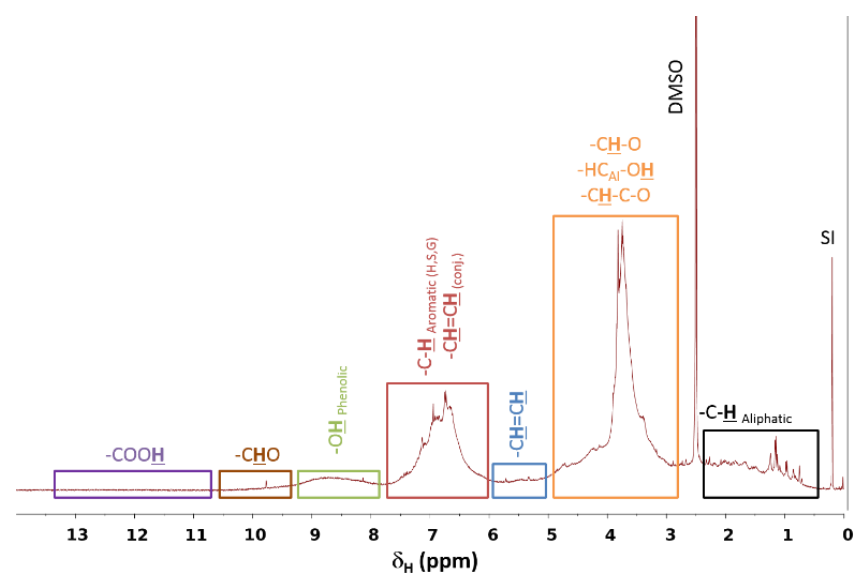

Figure 3: typical ${ }^{1} \mathrm{H}$ NMR spectra of Kraft lignin. $\mathrm{SI}=\mathrm{TKS}\left(\mathrm{Si}\left(\mathrm{SIMe}_{3}\right)_{3}\right)$.

Table 3: Quantitative data from ${ }^{1} \mathrm{H}$ NMR for initial lignin in $U_{H}{ }^{\text {a) }}$

\begin{tabular}{|c|c|c|c|c|c|}
\hline & Kraft & SEL & PEL & P1000 & Formic \\
\hline $\begin{array}{c}\underline{\mathbf{H}}_{\text {aliphatic }} \\
(0.5-2.3 \mathrm{ppm})\end{array}$ & 8.5 & 13.2 & 11.0 & 8.5 & 13.4 \\
\hline $\begin{array}{c}\underline{\mathbf{H}}_{\text {oxygenated aliphatic }} \\
\text { (dont } \mathrm{OC} \underline{H}_{3} \text { ) }\end{array}$ & 23.9 & 27.9 & 36.5 & 21.1 & 27.5 \\
\hline $\begin{array}{c}\underline{\mathbf{H}}_{\text {insaturated aliphatic }} \\
(5.1-5.8 \mathrm{ppm})\end{array}$ & 4.2 & 4.0 & 4.5 & 1.6 & 5.0 \\
\hline $\begin{array}{c}\underline{\mathbf{H}}_{\text {aromatic }} \\
(6.1-7.6 \mathrm{ppm})\end{array}$ & 14.1 & 13.3 & 10.6 & 7.9 & 8.9 \\
\hline $\begin{array}{c}\mathrm{O} \underline{\boldsymbol{H}}_{\text {phenolic }} \\
(8.0-9.2 \mathrm{ppm})\end{array}$ & 3.1 & 2.5 & 2.1 & 1.8 & 1.7 \\
\hline $\begin{array}{c}\text { C틍 } \\
(9.3-9.9 \text { ppm) }\end{array}$ & 0.2 & 0.5 & 0.4 & 0.3 & 0.4 \\
\hline $\begin{array}{c}\mathrm{COO} \underline{\mathbf{H}} \\
(10.9-13.6 \mathrm{ppm})\end{array}$ & 0.3 & 0.5 & 0.4 & 1.0 & 1.0 \\
\hline Total $\mathrm{H}$ & 54.3 & 61.9 & 65.5 & 42.1 & 57.9 \\
\hline $\mathrm{H}$ content $\left(\%_{\mathrm{wt}}\right)$ & 5.5 & 6.2 & 6.6 & 4.2 & 5.8 \\
\hline
\end{tabular}


$H$ content (\%wt)

(from Elemental Analysis)

5.3

6.4

6.5

5.6

5.7

Level of $\mathrm{H}$ analyzed by ${ }^{1} \mathrm{H}$

RMN (\%)

103

98

102

76

102

a) $U_{H}: \mathrm{mmol} \mathrm{H} / \mathrm{g}_{\text {lignin }}$

Although severe limitations due exist due to the low natural abundance of ${ }^{13} \mathrm{C}$ isomer, ${ }^{13} \mathrm{C}$ NMR is commonly used to characterize lignins ${ }^{130,134,135}$ as it allows observation of structural information like ether bonds or condensed aromatic moieties that cannot be observed in ${ }^{1} \mathrm{H}$ NMR. To gain quantitative information from these spectra, $\mathrm{Fe}(\mathrm{acac})_{3}$ was used as relaxing agent in order to homogenize relaxation time of various carbons encountered in lignins biopolymer and tetramethylthiourea $\left(\mathrm{SI}:\left(\mathrm{Me}_{2} \mathrm{~N}\right)_{2} \mathrm{CS}\right)$ was used as internal standard. Figure 4 shows typical ${ }^{13} \mathrm{C}$ NMR spectra of Kraft lignin (see Supporting Information for ${ }^{13} \mathrm{C}$ NMR spectra of other lignins). Table 4 summarized the data. Despite the use of relaxing agent, strong differences in relation time of the different carbons remain; therefore quantitative data are not accurate and are used with prudence. This limitation is supported by the low correlation between ${ }^{13} \mathrm{C}$ quantitative NMR analyses with data issued form elemental analyses. Nevertheless, data indicate, as expected, that most of the carbon in present in aromatic sub-units of lignins, whatever lignin considered (i.e. 52-62\% in $U_{c}$ ). Except SEL lignin the exhibit high content in aliphatic carbon (probably due to ethanol condensation during extraction process), all other lignins showed similar data. Noticeably, Formic lignin showed high COOR content probably due to formic/acetic acid extraction process.

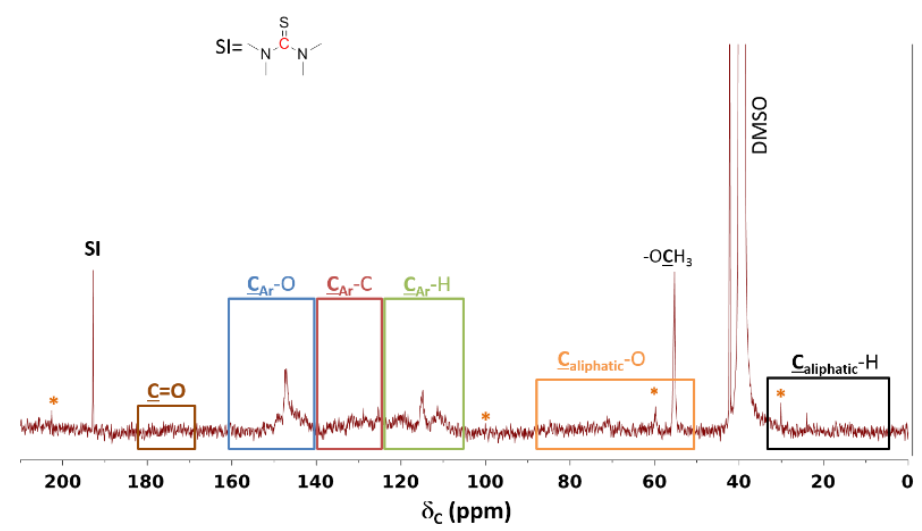

Figure 4: typical ${ }^{13} \mathrm{C}$ NMR spectra of Kraft lignin. $\mathrm{SI}=$ tetramethylthiourea used as internal standard $(\delta$ : $194.05 \mathrm{ppm}) .{ }^{*}=\mathrm{Fe}(\mathrm{acac})$ used as relaxing agent.

Table 4: Quantitative data from ${ }^{13} \mathrm{C}$ NMR for initial lignin in $\mathrm{U}^{\mathrm{a}}{ }^{\mathrm{a}}$

\begin{tabular}{cccccc}
\hline & Kraft & SEL & PEL & P1000 & Formic \\
\hline$\underline{C}_{\text {aliphatic }}$ & 4.2 & 12.7 & 4.9 & 1.6 & 5.2
\end{tabular}




\begin{tabular}{|c|c|c|c|c|c|}
\hline (36-10 ppm) & & & & & \\
\hline $\begin{array}{c}\underline{\mathrm{C}}_{3}-\mathrm{O} \\
(58-54 \mathrm{ppm})\end{array}$ & 2.7 & 5.1 & 4.6 & 3.8 & 2.2 \\
\hline $\begin{array}{c}\underline{\text { aliphatic }}^{-} \mathrm{O}\left(\text { hors } \mathrm{CH}_{3}-\mathrm{O}\right) \\
(90-53 \mathrm{ppm})\end{array}$ & 4.7 & 6.9 & 5.8 & 5.7 & 5.9 \\
\hline $\begin{array}{c}\underline{\mathbf{C}}_{\mathrm{Ar}}-\mathrm{H} \\
(125-102 \mathrm{ppm})\end{array}$ & 6.8 & 17.1 & 11.4 & 4.3 & 5.0 \\
\hline $\begin{array}{c}\left.\text { C }_{\text {Ar }}-\mathrm{C} \text { (dont } \mathrm{C}_{\mathrm{Al} \text {. ins. conj. }}\right) \\
\quad(142-125 \mathrm{ppm})\end{array}$ & 4.5 & 9.6 & 7.9 & 4.7 & 4.9 \\
\hline $\begin{array}{c}{\underline{\mathrm{C}_{\mathrm{Ar}}}}^{-} \mathrm{O} \\
(162-142 \mathrm{ppm})\end{array}$ & 6.4 & 10.3 & 6.2 & 7.8 & 7.6 \\
\hline $\begin{array}{c}\underline{\boldsymbol{C}}_{\text {aromatic }} \\
\left(\Sigma U_{c}: 162-102 \mathrm{ppm}\right)\end{array}$ & 17.7 & 37.0 & 25.5 & 16.8 & 17.5 \\
\hline $\begin{array}{c}\text { COOR }(R=H \text { ou alkyl) } \\
\quad(166-175 \text { ppm })\end{array}$ & 1.0 & 1.4 & 0.9 & 1.4 & 2.9 \\
\hline Total $\underline{\mathrm{C}}$ & 30.3 & 63.2 & 41.7 & 29.3 & 33.8 \\
\hline C content $\left(\%_{w t}\right)$ & 36.4 & 75.9 & 50.1 & 35.2 & 40.6 \\
\hline $\begin{array}{c}\text { C content (\%wt) } \\
\text { (from Elemental Analysis) }\end{array}$ & 62.5 & 66.2 & 63.0 & 61.8 & 59.9 \\
\hline $\begin{array}{c}\text { Level of C analyzed by }{ }^{13} \mathrm{C} \\
\text { RMN (\%) }\end{array}$ & 58 & 115 & 79 & 57 & 68 \\
\hline
\end{tabular}

Accurate quantitative data regarding functional $\mathrm{OH}$ groups can be gain from ${ }^{31} \mathrm{P}$ NMR after suitable

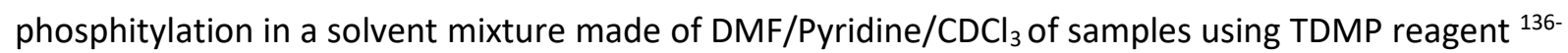
${ }^{140}$. Thus, it is possible to quantify $\mathrm{OH}$ groups engaged in various lignin sub-units like aliphatic, Syringyl, condensed, guaiacyl, hydroxyphenyl and carboxylic acid. Therefore, this method helps to point out differences in lignin samples depending on origin and extraction process. Figure $\mathbf{5}$ shows a typical ${ }^{31} \mathrm{P}$ NMR spectra of Kraft lignin obtained after phosphitylation (see Supporting Information for ${ }^{31} \mathrm{P}$ NMR spectra of other lignins). Different region of ${ }^{31} \mathrm{P}$ NMR spectra can be separated and integrated to furnish quantitative data: aliphatic $\mathrm{OH}$ [145.4-150.0 ppm], syringyl $\mathrm{OH}$ and $\mathrm{OH}$ in condensed units [140.0-144.5 ppm], guaiacyl OH [138.7-140.2 ppm], p-hydroxyphenyl OH [136.9-138.6 ppm] and carboxylic acid $\mathrm{OH}$ [134.0-136.0]. Quantitative data obtained from such spectra are summarized in Table 5. Main differences concern: 
a) the aliphatic $\mathrm{OH}$ region for which the Organosolv SEL and PEL lignins exhibited higher oxygen content than the other lignin (i.e. 2.5-2.9 $\mathrm{U}_{0}$ versus 1.4-1.8 $\mathrm{U}_{0}$ ) that is related to the method of extraction; noticeably the third Organosolv Formic lignin did not showed such a behavior probably due to formation of esters;

b) Kraft and Organosolv SEL lignins exhibited low oxygen content in the "syringyl+condensed units" region as they contain only guaiacyl units due to their botanic origin (i.e. 0.9-1.4 U。 versus 0.8-2.1 $\mathrm{U}_{\mathrm{o}}$ ). Again, the Formic lignin showed here a low oxygen content that can be either related to participation of phenolic $\mathrm{OH}$ to esters groups or low ratio of condensed units linked to the relative soft conditions of extraction;

c) As expected, Kraft and Organosolv SEL lignins showed higher oxygen content in the guaiacyl region (i.e. 1.6-2.0 $\mathrm{U}_{\mathrm{o}}$ versus 0.7-0.9 $\mathrm{U}_{\mathrm{O}}$ ) given their botanic nature;

d) As expected form their botanic origin Formic and P1000 lignins exhibited higher oxygen content in the $p$-hydroxyphenyl $\mathrm{OH}$ region (i.e. 0.3-0.5 $\mathrm{U}_{0}$ versus $\approx 0.1 \mathrm{U}_{\mathrm{O}}$ ). They also exhibited, for the same reason, higher oxygen content in the carboxylic $\mathrm{OH}$ region (i.e. 0.5-0.9 $\mathrm{U}_{\mathrm{o}}$ versus $\left.\approx 0.2 \mathrm{U}_{0}\right)$

Finally, data showed that the Formic lignin exhibited lower oxygen content by ${ }^{31} \mathrm{P}$ NMR that is mainly related to the formation of esters during the extraction process according other analyses. Additionally, only $c a 30 \%$ of the total oxygen can be quantified by the ${ }^{31} \mathrm{P}$ NMR (compared to the values obtained from elemental analyses) attesting that most of the oxygen are engaged in ether and esters bonds, and also in functional groups like aldehydes, according the generally accepted lignin structure.

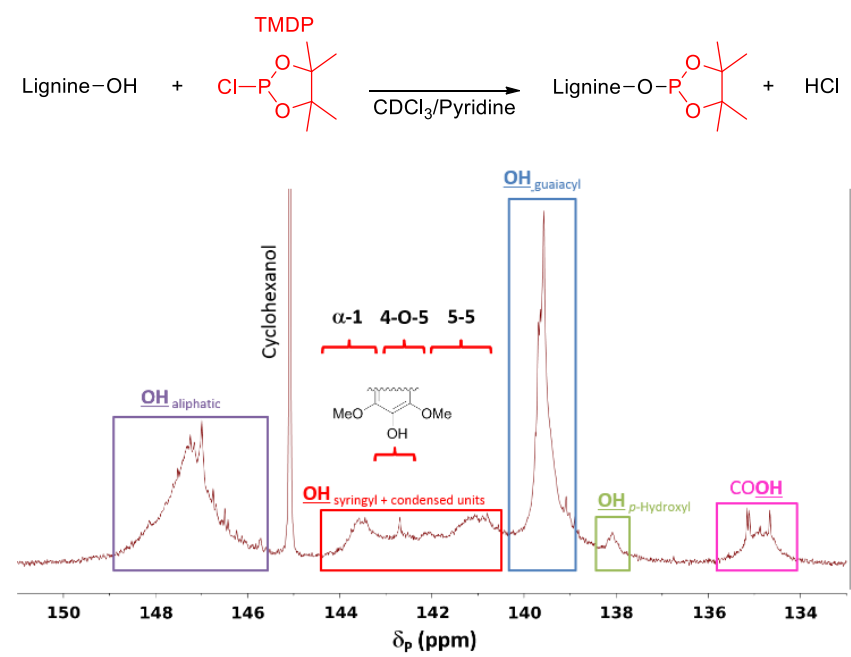

Figure 5: typical ${ }^{31} \mathrm{P}$ NMR spectra of Kraft lignin after phosphitylation using TDMP reagent. Cyclohexanol is used as internal standard and is phosphitylated together with lignin sample $(\delta: 145.08$ ppm).

Table 5: Quantitative data from ${ }^{31} \mathrm{P} N M R$ for initial lignin in $\mathrm{U}_{0}{ }^{\mathrm{a}}$ ) 


\begin{tabular}{|c|c|c|c|c|c|}
\hline & Kraft & SEL & PEL & P1000 & Formic \\
\hline $\begin{array}{c}\underline{\text { OH}}_{\text {aliphatic }} \\
(149.1-145.6 \text { ppm) }\end{array}$ & 1.8 & 2.5 & 2.9 & 1.4 & 1.5 \\
\hline $\begin{array}{l}\underline{\mathrm{OH}}_{\text {syringyl }+ \text { condensed units }} \\
(144.3-140.2 \mathrm{ppm})\end{array}$ & 1.4 & 0.9 & 1.6 & 2.1 & 0.8 \\
\hline $\begin{array}{c}\underline{\mathrm{OH}}_{\text {guaiacyl }} \\
(140.2-138.7 \mathrm{ppm})\end{array}$ & 1.6 & 2.0 & 0.7 & 0.9 & 0.7 \\
\hline 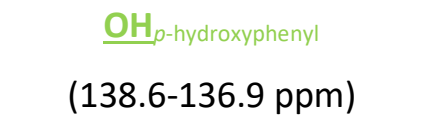 & 0.2 & 0.1 & 0.0 & 0.5 & 0.3 \\
\hline $\begin{array}{c}\underline{\mathrm{OH}}_{\text {carboxylic acids }} \\
(135.6-134.0 \mathrm{ppm})\end{array}$ & 0.3 & 0.2 & 0.1 & 0.9 & 0.5 \\
\hline Total $\underline{\mathbf{O}}$ & 5.3 & 5.6 & 5.4 & 5.9 & 3.8 \\
\hline 0 content $\left(\%_{w t}\right)$ & 8.5 & 9.0 & 8.6 & 9.4 & 6.1 \\
\hline $\begin{array}{c}\text { O content (\%wt) } \\
\text { (from Elemental analysis) }\end{array}$ & 29.1 & 26.1 & 30.0 & 29.5 & 31.9 \\
\hline $\begin{array}{l}\text { Level of O analyzed by }{ }^{31} \mathrm{P} \\
\text { RMN (\%) }\end{array}$ & 29 & 34 & 29 & 32 & 19 \\
\hline
\end{tabular}

a) $\mathrm{U}_{\mathrm{o}}: \mathrm{mmol} \mathrm{O} / \mathrm{g}_{\text {lignin }}$

Further structural characterizations were obtained from HSQC NMR spectra involving INPET sequence ${ }^{129-131,141-143}$. Signal identification and characterization was made on the basis of previously described literature ${ }^{130,142-149}$. According to literature, HSQC NMR spectra are divided in three regions, the aliphatic region $\left[0.5-5 \mathrm{ppm}{ }^{1} \mathrm{H} / 0-50 \mathrm{ppm}{ }^{13} \mathrm{C}\right]$, the oxygenated aliphatic region $\left[2.5-6 \mathrm{ppm}{ }^{1} \mathrm{H} / 50\right.$ $105 \mathrm{ppm}{ }^{13} \mathrm{C}$ ] and the aromatic region [4.9-8.5 ppm ${ }^{1} \mathrm{H} / 90-160 \mathrm{ppm}{ }^{13} \mathrm{C}$ ]. Generally, aliphatic region is not exploited as it provide only little structural information. Figure $\mathbf{6}$ and $\mathbf{7}$ show typical oxygenated aliphatic (Figure 6) and aromatic (Figure 7) regions for Kraft lignin with key structural identifications (see Supporting Information for HSQC spectra of other lignins). Oxygenated aliphatic region allowed to detect the presence of residual carbohydrates in almost all lignin samples $\left(\delta_{H} / \delta_{c}: 2.87-3.87 / 65.7-\right.$ $84.5 \mathrm{ppm}$ ) with a lower content for those issued from Organosolv processes, the methoxy groups $\left(\delta_{\mathrm{H}} / \delta_{\mathrm{c}}: 3.77 / 56.3 \mathrm{ppm}\right)$ omnipresent in lignins and several types of bonds between aromatic moieties: $\beta-0-4$ ( $A$ ), $\beta-\beta$ (B) et $\beta-5$ (C). This region is very informative regarding structural modifications of lignins either due to extraction processes or chemical conversions. The most common inter-unit bond is the $\beta-0-4\left(A / A^{\prime} / A^{\prime \prime}\right)$ whatever the lignin considered. It is possible to distinguish the guaiacyl units $\left(\delta_{H} / \delta_{c}\right.$ : 4.31/84.5 ppm) from the syringyl units ( $\left.\delta_{H} / \delta_{C}: 4.15 / 86.6 \mathrm{ppm}\right)$. HSQC analysis confirmed that Formic lignin contain low ratio of inter-units bonds compared to other involved lignins as only $A_{\alpha}\left(\delta_{H} / \delta_{c}\right.$ : 
4.79/71.5 ppm), $A_{\gamma}\left(\delta_{H} / \delta_{c}: 3.31 / 60.7 p p m\right), B_{\alpha}\left(\delta_{H} / \delta_{c}: 4.65 / 85.7 p p m\right)$ et $C_{\alpha}\left(\delta_{H} / \delta_{c}: 5.5 / 87.4 p p m\right)$ correlations can be observed. This agree with previous reports from literature for similar lignins ${ }^{150,151}$. Aromatic region exhibits characteristic correlation related to the nature of the aromatic present in samples. For softwood lignins (i.e. Kraft and Organosolv SEL), correlation corresponding to the guaiacyl

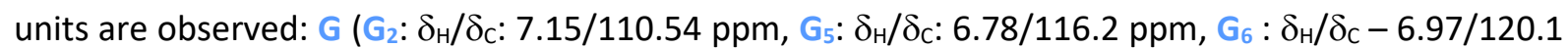
ppm) et $H\left(H_{2,6}: \delta_{H} / \delta_{c}: 7.1 / 129 \mathrm{ppm}\right)$ whereas those issued from hardwood or annual plants (i.e. Organosolv PEL, Formic and P1000) exhibited additionally correlation related to syringyl units: $\mathbf{S}\left(\mathbf{S}_{2,6}\right.$ : $\left.\delta_{H} / \delta_{c}: 6.85 / 104.7 \mathrm{ppm}, \mathbf{S}_{2,6}^{\prime}: \delta_{H} / \delta_{c}: 6.57 / 106.28 \mathrm{ppm}\right)$. Noticeably, Kraft lignin exhibited additional correlation related to unsaturated compounds $\left(\delta_{\mathrm{H}} / \delta_{\mathrm{c}}: 5.35 / 130 \mathrm{ppm}\right)$ attesting the formation of stilbene units during the extraction process.
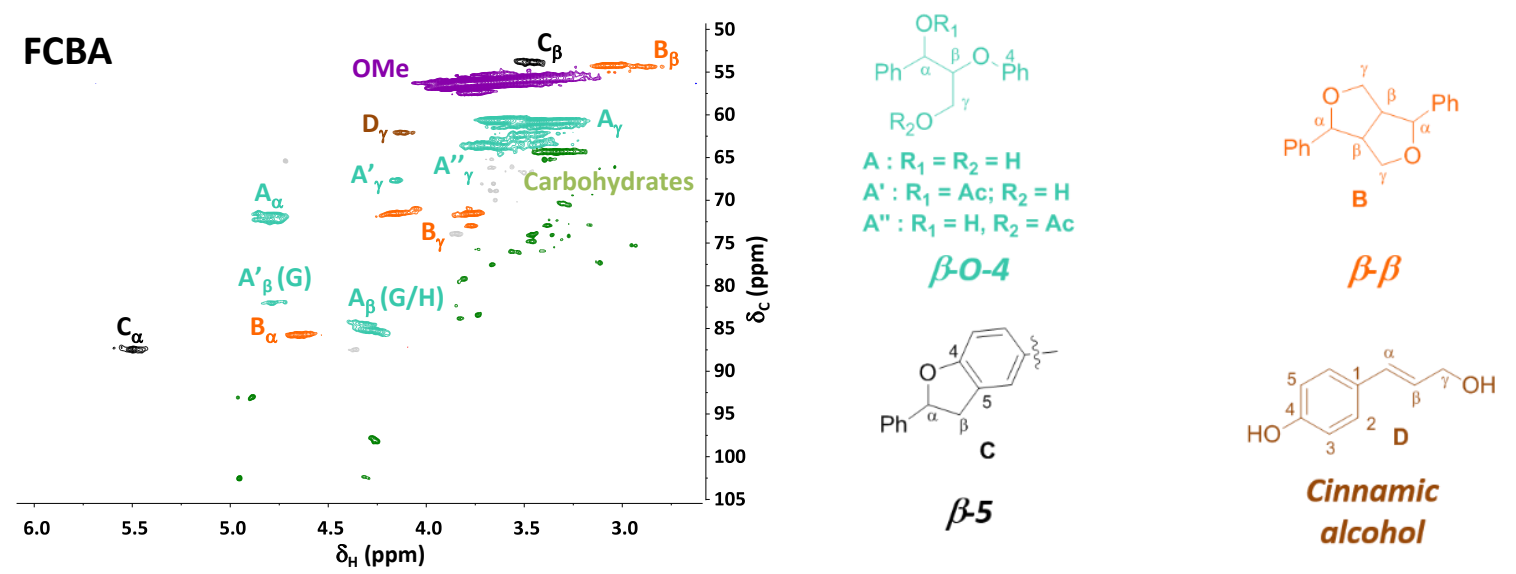

Figure 6: typical HSQC NMR spectra of Kraft lignin (Oxygenated aliphatic region) with key structural identification.
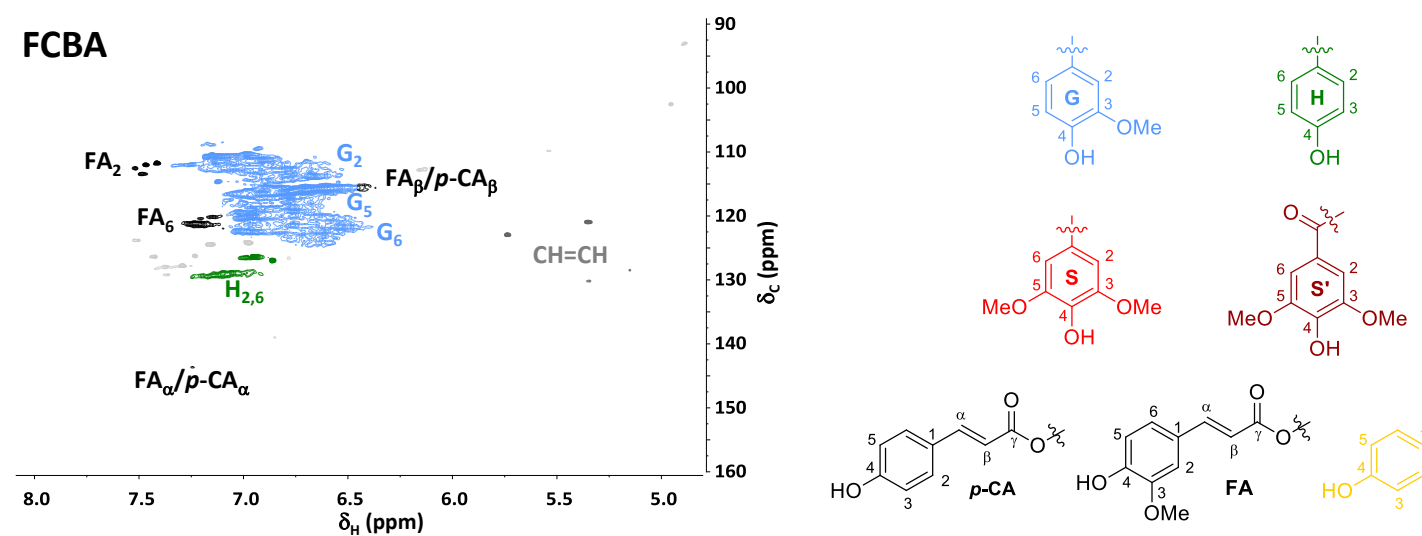

Figure 7: typical HSQC NMR spectra of Kraft lignin (Aromatic region) with key structural identification. Semi quantitative $\mathrm{G} / \mathrm{S} / \mathrm{H}$ units composition can be obtained from HSQC spectra applying the volume integration ${ }^{152}$. Data are collected in Table 6 and agree with value generally reported in the literature. These data will be informative when addressing lignin conversion. 
Table 6: Semi quantitative analysis regarding $\mathrm{G} / \mathrm{S} / \mathrm{H}$ composition of initial lignins.

\begin{tabular}{ccccc}
\hline Kraft & SEL & PEL & P1000 & Formic \\
\hline & & G/S/H & \\
\hline $88 / 0 / 12$ & $96 / 0 / 4$ & $63 / 35 / 2$ & $53 / 34 / 13$ & $65 / 21 / 14$ \\
\hline
\end{tabular}

To summarize these analyses, as expected, Kraft and SEL lignins issued from softwood contain mainly guaiacyl units, syringyl ones being only observed for PEL (hardwood), P1000 and Formic (annual plants) lignin. Additionally, P1000 and Formic lignins showed high content of p-hydroxyphenyl units that is to expect for lignins produced from wheat straw. These analyses also indicated that Organosolv extraction processes allowed better biomass fractionation as SEL, PEL and Formic lignins showed lower residual carbohydrate content. Finally, Organosolv lignins exhibited higher aliphatic proton content due to extraction process either via ester formation (i.e. Formic) confirmed by ${ }^{13} \mathrm{C}$ and ${ }^{31} \mathrm{P}$ NMR or condensation reactions with ethanol (i.e. SEL and PEL) as supported by ${ }^{31} \mathrm{P}$ NMR.

\section{Studies on lignin depolymerization under oxidative atmosphere}

\section{Designing the experimental protocol}

The complexity of the reaction mixture obtained after a depolymerization experiment (see experimental) encouraged us to design a protocol allowing careful evaluation of the transformation that occurred during the reaction. The main questions concerned optimization of the fractionation procedures in order to ensure reproducible results and to achieve relative selective separation of the different reaction products allowed thus careful analyses of different reaction products by complementary techniques.

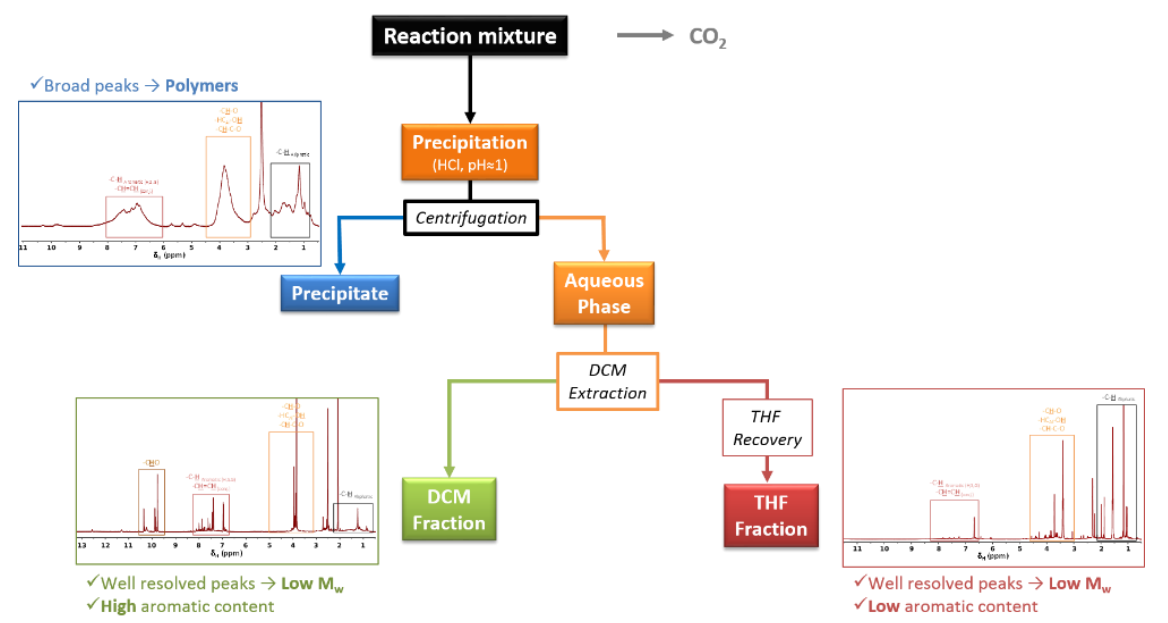

Figure 8: Schematic representation of fractionation protocol used for treating the reaction mixture after the reaction 
Several experiments were conducted before achieving a fractionation procedure (Figure 8). For example, we found that replacing sulfuric acid by hydrochloric acid to precipitate non liquefied lignin allowed better removal of salts and avoided pollution of the product due to side reaction with extraction solvents (i.e. THF). Additionally, we found that the use of dichloromethane (DCM), while less efficient, in the place of diethyl ether or ethyl acetate allowed selective extraction of the aromatic compounds from the reaction. Thus, three distinct fractions were obtained those spectroscopic characteristics differed. The precipitate provided spectroscopic data close to those observed for lignin type structures corresponding to polymers, the THF fraction showed signals corresponding to low molecular weight "mainly aliphatic" oligomeric compounds without aromatic signals and the DMC fraction exhibited well resolved spectra characteristic of aromatic products. With such fractionation protocol, the mass balance is generally between $85 \%$ and $99 \%$ depending on the relative importance of gas phase and the loss of low molecular weight compounds during extractions procedure.

\section{Influence of the reaction conditions on lignin conversion}

Several reaction conditions (base concentration, temperature, pressure, stirring rate) were evaluated using Kraft lignin. The results were then expressed in term of lignin fractionation, i.e. the respective mass of products obtained in DCM, THF and precipitate fractions in regards to the initial mass of lining engaged in the reaction, and in terms of yields in most observed aromatic compounds (i.e. vanillin, acetovanillone and vanillic acid). The lignin conversion was arbitrarily defined from the mass of precipitate that was considered as non-liquefied part of lignin, given that this precipitate is functionally/structurally different from the initial biopolymer (see below).

Initial conditions were arbitrarily fixed as: $150^{\circ} \mathrm{C}, \mathrm{P}_{\text {air }}$ : 40 bar, $1 \mathrm{~h}, \mathrm{Clignin}_{\mathrm{n}}: 5 \mathrm{~g} / \mathrm{L}, 1500 \mathrm{rpm}^{153}$. It was observed that the presence of a base plays a crucial role on lignin transformation. At neutral or acidic $\mathrm{pH}$, lignin conversion is low (i.e; $<5 \%$ ) whereas under basic conditions the conversion depends strongly on the sodium hydroxide loading. Thus increasing the $\mathrm{NaOH}$ loading from $4 \mathrm{~g} / \mathrm{L}$ to $10 \mathrm{~g} / \mathrm{L}$ allowed to increase lignin conversion from $70 \%$ to $90 \%$. At the same time, the yields of vanillin, acetovanillone and vanillic acid growth from ca. $0.1 \%$ to $1.5 \%, 0.5 \%$ and $0.2 \%$ resp. Regarding the precipitate, FTIR spectroscopy showed strong modifications of the biopolymer as the characteristic bands of primary and secondary alcohols at 1032 and $1082 \mathrm{~cm}^{-1}$ resp. and that of aromatic skeleton at $1512 \mathrm{~cm}^{-1}$ disappeared while those attributed of carbonyls groups at 1595 and $1714 \mathrm{~cm}^{-1}$ increased. These transformations were supported by NMR analyses that showed that almost all signals attributed to inter-unit bonds (i.e. $\beta-0-4, \beta-\beta, \beta-5$ ) disappeared (i.e. $\delta_{H} / \delta_{c}$ : 4.31/84.5 ppm; 4.15/86.6 ppm; 4.79/71.5 ppm; 3.31/60.7 ppm; 4.65/85.7 ppm and 5.5/87.4 ppm - see Figure 6), those characteristic of aromatic moieties decreased (i.e. $\delta_{\mathrm{H}} / \delta_{\mathrm{c}}: 7.15 / 110.54$ ppm; 6.78/116.2 ppm; 6.97/120.1 ppm and 7.1/129 ppm 
- see Figure 7) whereas signals indicated the formation of conjugated double bonds to carboxylic acids (i.e. $\left.\delta_{H} / \delta_{c}: 6.8-7.7 / 123-132 \mathrm{ppm}\right)$.

Increasing the reaction temperature from $50^{\circ} \mathrm{C}$ to $150^{\circ} \mathrm{C}$ allowed to increase lignin conversion from $19 \%$ at $50^{\circ} \mathrm{C}, 47 \%$ at $100^{\circ} \mathrm{C}$ to $89 \%$ at $150^{\circ} \mathrm{C}$. At the same time, yields in vanillin increased from $0.6 \%$ at $50^{\circ} \mathrm{C}$ to $2.2 \%$ at $150^{\circ} \mathrm{C}$. However, at $150^{\circ} \mathrm{C} 9 \%$ mass loss was observed by evolution of volatile compounds in gas phase. Air pressure plays also, while less pronounced, a role. While at $P_{\text {air }}=10 \mathrm{bar}$ lignin conversion stay limited to $43 \%$, it reached $80 \%$ at $\mathrm{P}_{\text {air }}=20$ bar and $89 \%$ at $\mathrm{P}_{\text {air }}=40$ bar. However, at 40 bar the yields in vanillin decreased to $2.2 \%$ (versus $2.8 \%$ at 20 bar); therefore, further reactions were performed at $\mathrm{P}_{\text {air }}=20$ bar.

In summary, this parametric study allowed us to select the reaction conditions to perform lignin depolymerization under oxidative atmosphere: $\mathrm{T}: 150^{\circ} \mathrm{C}, \mathrm{P}_{\text {air }}: 40 \mathrm{bar}, 1 \mathrm{~h}, \mathrm{C}_{\text {lignin }}: 5 \mathrm{~g} / \mathrm{L}, \mathrm{C}_{\mathrm{NaOH}}: 10 \mathrm{~g} / \mathrm{L}$, 1500 rpm.

\section{Depolymerization of various lignins}

The five lignins previously characterized were engaged in the depolymerization study under the conditions selected and described above.

After fractionation, it was observed that Kraft and SEL lignins that contain mainly guaiacyl unit led to $56 \%$ and $44 \%$ conversion, respectively. Lignins that contain syringyl units and guaiacyl units, like PEL, P1000 and Formic lignins exhibited higher conversion rates with $85 \%_{w t}, 79 \%_{w t}$ and $81 \%_{w t}$ resp. (Figure 9). However, the last lignins led to mass loss due to evolution of products in gas phase (resp. $10 \%, 19 \%$ and $21 \%)$. In all cases the DCM fraction represent little part of the products, generally between $9 \%_{\mathrm{wt}}$ to $19 \%$ wt. In the case of P1000 and Formic lignins, the low ratio of the DCM fractions can be related to the comparatively high mass-loss in gas phase. Noticeably, the higher lignin conversion observed for the syringyl containing biopolymers is related to high ratio of THF fraction (i.e. 51-56\% ${ }_{\text {wt }}$ for PEL, P1000 and Formic lignins versus $29-39 \%$ wt for Kraft and SEL lignins).

The precipitate was analyzed by FTIR and NMR; the comments reported above applied as well in these cases: strong modifications of the biopolymer as attested by the disappearance of the bands at 1032 $\mathrm{cm}^{-1}, 1082 \mathrm{~cm}^{-1}$ (i.e. alcohols) and $1512 \mathrm{~cm}^{-1}$ (aromatic skeleton) and the increase of the bands at 1595 $\mathrm{cm}^{-1}$ and $1714 \mathrm{~cm}^{-1}(\mathrm{C}=0)$ in FTIR spectroscopy, and in NMR spectra, the disappearance of the signals attributed to $\beta-0-4, \beta-\beta, \beta-5$ inter-unit bonds associated to a decrease in intensity of signals characteristic of aromatic moieties and the apparition of signals indicating the formation of conjugated double bonds to carboxylic acids were observed. The THF fraction was analyzed by NMR showing that it generally contain no aromatic moieties correlated to relative high content in aliphatic sub-structures. 
GCMS analyzed revealed the presence of succinic, fumaric, maleic and muconic acids, however; in low ratio. Further attempts to characterize this complex mixture by HPLC-MS failed to date. Analysis of the DCM fractions by GC indicated that generally the yields in ketones, i.e. acetovanillone and/or acetosyringone stayed limited to nearly $0.5 \%$ wt (Figure 10). For lignins issued from softwoods (i.e. Kraft and SEL), relative high amount of acid (i.e. vanillic acid) was produced (i.e. $1.1 \%_{w t}$ and $1.8 \%_{w t}$, resp.). Aldehydes stayed the main compounds in all cases, however differences could be observed. Lignins produced from annual plants (here, wheat straw) led to relatively low yields in aldehydes with $1.9 \%_{\mathrm{wt}}$ and $1.4 \%$ wt for P1000 and Formic lignins resp. that can be related to over oxidation of the products as supported by the relative high mass-loss in gas phase. Other lignins issued from woods gave reasonable yields in aldehydes; those extracted from softwoods like Kraft and SEL lignin gave $2.4 \%_{w y}$ and $3.9 \%_{w t}$ resp. showing the interest of the ethanol Organosolv process for lignin extraction in this work, that extracted from hardwood led to $4.4 \%$ wt yield in aldehydes indicating that lignin containing syringyl units are more suitable for oxidative depolymerization ${ }^{154,155}$.

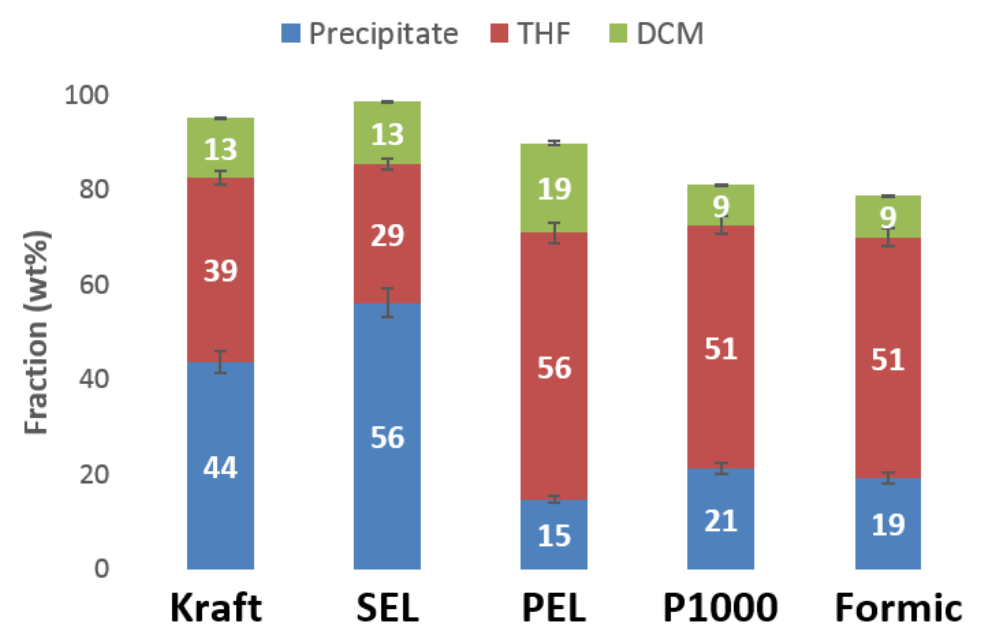

Figure 9: Influence of the nature of lignins in their conversion. Conditions: $150^{\circ} \mathrm{C}, \mathrm{P}_{\text {air }}: 20 \mathrm{bar}, 1 \mathrm{~h}, \mathrm{C}_{\text {lignin }}$ : $5 \mathrm{~g} / \mathrm{L}, \mathrm{C}_{\mathrm{NaOH}}: 10 \mathrm{~g} / \mathrm{L}, 1500 \mathrm{rpm}$. 


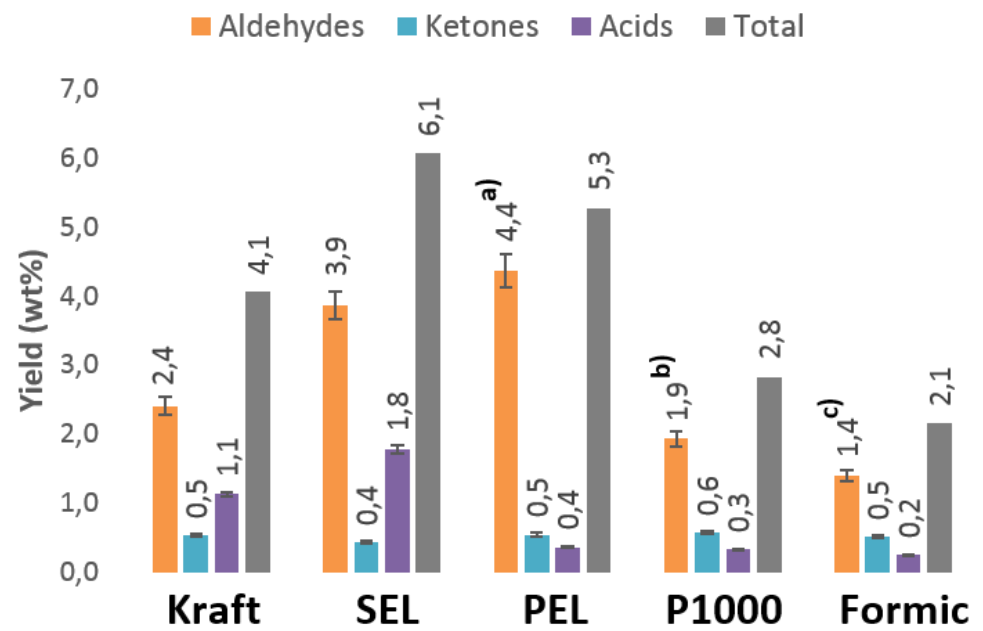

Figure 10: Yields in main aromatic compounds contained in DCM fraction after treatment of various lignins under air. Conditions: $150^{\circ} \mathrm{C}, \mathrm{P}_{\text {air: }}: 20$ bar, $1 \mathrm{~h}, \mathrm{C}_{\text {lignin }}: 5 \mathrm{~g} / \mathrm{L}, \mathrm{C}_{\mathrm{NaOH}}: 10 \mathrm{~g} / \mathrm{L}, 1500 \mathrm{rpm}$. ${ }^{\text {a) }}$ inlc. $2.8 \%$ synringaldehyde and $1.5 \%$ vanillin. ${ }^{\text {b) }}$ inlc. $0.8 \%$ synringaldehyde and $1.1 \%$ vanillin. ${ }^{\text {c) }}$ inlc. $0.4 \%$ synringaldehyde and $1.0 \%$ vanillin.

Further information came from analyzing the evolution of the reaction mixture versus the time. For this several experiments were conducted for a given reaction time between $1 / 2 h$ to $5 h$. Three of the initial five lignins were engaged in this detailed study, P1000 and Formic lignins given the mass-loss in gas phase were not further evaluated.

Figure 11 represent the evolution of the different fraction of products versus the time. The time $t=0 \mathrm{~h}$ correspond to the time at which the desire reaction temperature was reached. Treating the reaction mixture immediately after this time indicated that during heating no lignin modifications occurred as the data are identical to those achieved when carrying out the fractionation protocol on initial lignins. Data show increase of mass-loss as the reaction time increase that is correlated with evolution of product in gas phase, including carbon dioxide. After $5 \mathrm{~h}$ the mass balance is of $88 \%_{\mathrm{wt}}$ for the Kraft and the SEL lignins and of $60 \%$ wt for the PEL lignin. At the same time, it was observed that the amount of precipitate decrease rapidly during the first hour of reaction to stabilized at $c a .15 \%$ wt. The THF fraction increase during the first hour to reach $50 \%_{w t}-66 \%_{w t}$ before remaining almost stable; the DCM fraction increase also during the first hour to reach $13-15 \%$ wt before decreasing probably due to over oxidation of aromatic compounds obtained by lignin depolymerization.

Analyzing DCM fraction by GC (Figure 12) showed that the maximum yields in aromatic compounds were reached in $15 \mathrm{~min}$. Thus after $15 \mathrm{~min}, 2.2 \%_{\mathrm{wt}}, 4.5 \%_{\mathrm{wt}}$ and $5.0 \%_{\mathrm{wt}}$ (incl. 1.1\% $\%_{\mathrm{wt}}$ vanillin and $3.9 \%_{\mathrm{wt}}$ syringaldehyde) yields in aldehydes were achieved for the Kraft, SEL and PEL lignins, resp. After 15 min, the yields decreased more or less rapidly due to product degradation by over oxidation. Data indicate 
that syringaldehyde is more sensitive to over oxidation as the yield decreases rapidly all-over the time to give after $5 \mathrm{~h}$ only $0.5 \%$ wt yield. Additionally, these analyses indicated that also that all main aromatic compounds, aldehydes, ketones and acids, are formed simultaneously, particularly acids did not correspond to over oxidation of aldehydes.
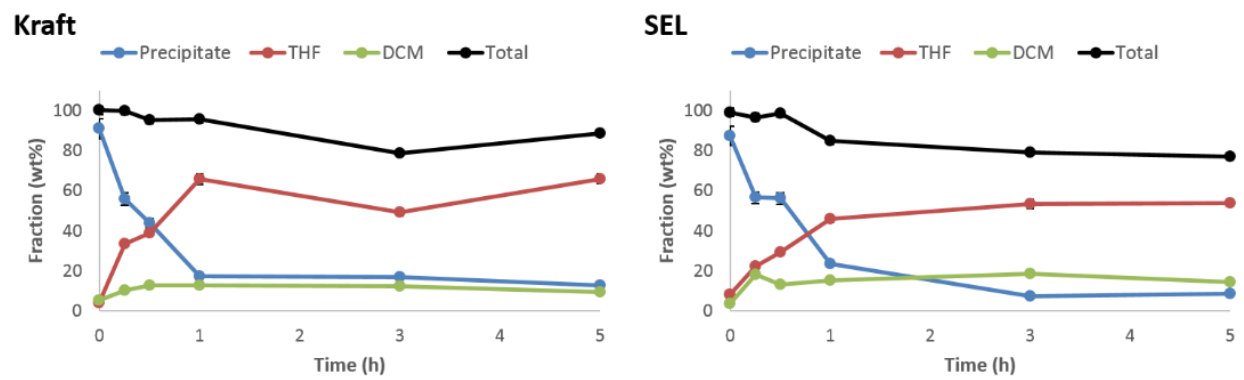

PEL

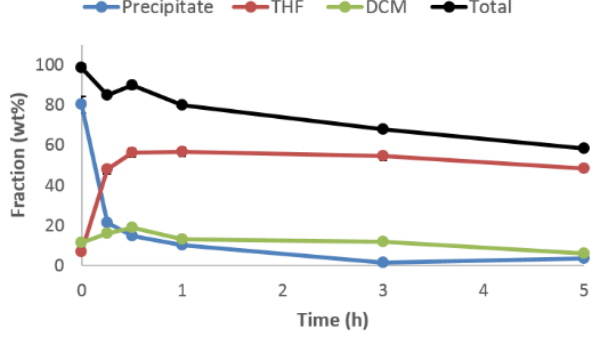

Figure 11: evolution of the three product fractions (i.e; precipitate, DCM and THF) versus the time for Kraft, SEL and PEL lignins. Each point corresponds to an experiment. Conditions: $150^{\circ} \mathrm{C}, \mathrm{P}_{\text {air }}$ : 20 bar, $C_{\text {lignin: }}$ 5g/L, $\mathrm{C}_{\mathrm{NaOH}}: 10 \mathrm{~g} / \mathrm{L}, 1500 \mathrm{rpm}$.
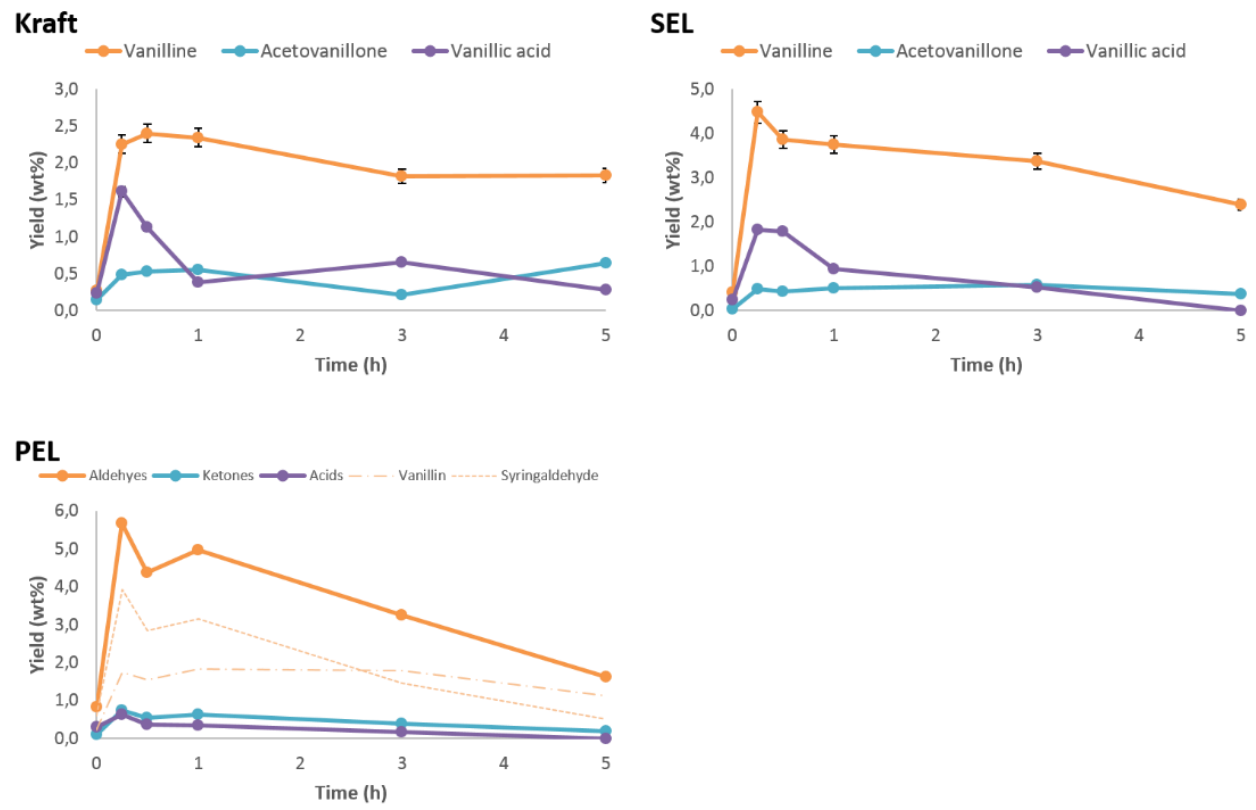

Figure 12: evolution of the yields in main aromatic compounds in DCM fraction versus the time for Kraft, SEL and PEL lignins. Each point corresponds to an experiment. Conditions: $150^{\circ} \mathrm{C}, \mathrm{P}_{\text {air }}$ : 20 bar, $C_{\text {lignin: }} 5 \mathrm{~g} / \mathrm{L}, \mathrm{C}_{\mathrm{NaOH}}: 10 \mathrm{~g} / \mathrm{L}, 1500 \mathrm{rpm}$. 
The precipitate fractions were analyzed by FTIR spectroscopy (Figure 13). It was observed that the bands characteristic of aromatic skeleton at $1515 \mathrm{~cm}^{-1}$ (together with the band at $1600 \mathrm{~cm}^{-1}$, however, its evolution was masked partly by increase due to formation of carbonyl functionalities) decreased, as well as those characteristic of guaiacyl units at $1270 \mathrm{~cm}^{-1}$ and syringyl units at $1329 \mathrm{~cm}^{-1}$ and 1115 $\mathrm{cm}^{-1}$ (for the PEL lignin only). Additionally, the bands characteristic of primary alcohols at $1030 \mathrm{~cm}^{-1}$ decreased. At the same time, the bands characteristic of carbonyl functions at $1700 \mathrm{~cm}^{-1}$ increased attesting of oxidation of the biopolymer. Integrating these bands provided information about the relative rate of transformation. For the Kraft lignin data showed that after 30 min reaction time the bands at $1515 \mathrm{~cm}^{-1}$ and $1032 \mathrm{~cm}^{-1}$ decreased by the half, decrease reaching $75 \%$ after $5 \mathrm{~h}$. Variation for the band at $1270 \mathrm{~cm}^{-1}$ attributed to guaiacyl unit was less pronounced as it decrease of "only" 40\% after $5 \mathrm{~h}$ that can be related to the concomitant formation of new guaiacyl units by oxidation of the biopolymer ${ }^{156}$. These variations were linked to relative rapid increase of the band at $1700 \mathrm{~cm}^{-1}$ those integral doubled within $30 \mathrm{~min}$. Evolution was almost the same for the SEL lignin, data indicated that the bands at $1515 \mathrm{~cm}^{-1}$ and $1032 \mathrm{~cm}^{-1}$ decreased by $20 \%$ after $15 \mathrm{~min}$, decrease reaching $80 \%$ after $5 \mathrm{~h}$. But variation for the band at $1270 \mathrm{~cm}^{-1}$ attributed to guaiacyl unit was not as affirmative as initially an increase of the band was observed (ca. 20-25\% during the first $3 \mathrm{~h}$ ) before decreasing again to reach finally a decrease of $10 \%$ after $5 \mathrm{~h}$. These observations can be related to the difference of extraction process, the Organosolv lignins being more sensitive to oxidation and therefore leading easily to creation of new guaiacyl units in larger amount. Like for Kraft lignin, the band at $1700 \mathrm{~cm}^{-1}$ gain quickly in intensity. For the PEL lignin, data indicated that the bands at $1515 \mathrm{~cm}^{-1}$ and $1032 \mathrm{~cm}^{-1}$ decreased by $40-50 \%$ after $1 \mathrm{~h}$, decrease reaching $65 \%$ after $5 \mathrm{~h}$. But variation for the band at $1329 \mathrm{~cm}^{-1}$ attributed to syringyl unit was not as affirmative as initially it remain constant before decreasing by $10 \%$ after 5 h. Unexpectedly, the band at $1118 \mathrm{~cm}^{-1}$ also characteristic of syringyl units decreased of $20 \%$ after 1 hour, reaching a decrease of $50 \%$ after 5 h; however this band could be superimposed with those attributable to secondary alcohols that could be oxidized more rapidly. These observations support previous explanation related to Organosolv lignins. Like for other lignins, the band at $1700 \mathrm{~cm}^{-1}$ gain quickly in intensity. 

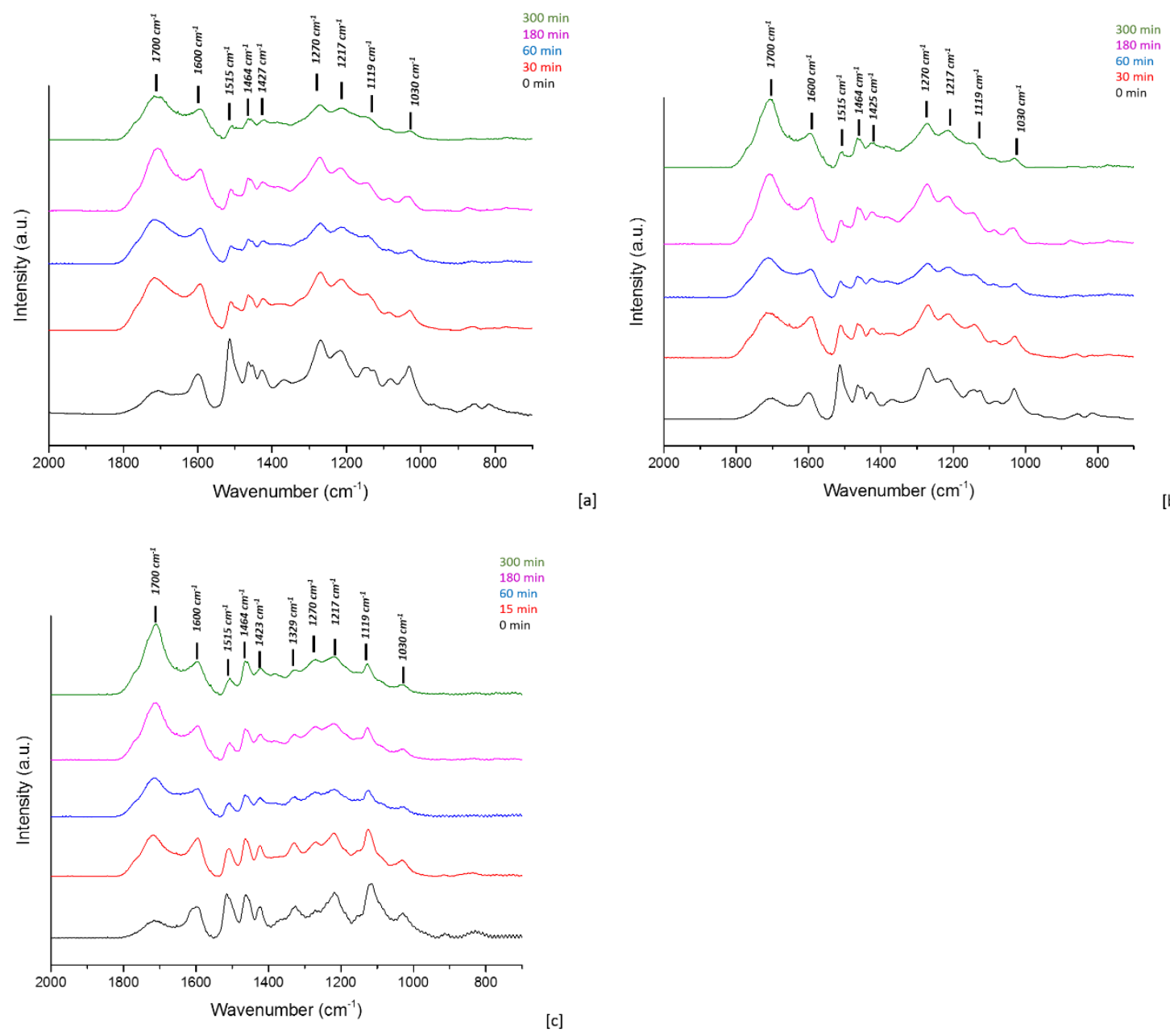

Figure 13: evolution of the precipitate functional characteristics versus the time for Kraft [a], SEL [b] and PEL [C] lignins. Conditions: $150^{\circ} \mathrm{C}, \mathrm{P}_{\text {air: }} 20$ bar, $\mathrm{C}_{\text {lignin }}: 5 \mathrm{~g} / \mathrm{L}, \mathrm{C}_{\mathrm{NaOH}}: 10 \mathrm{~g} / \mathrm{L}, 1500 \mathrm{rpm}$.

Precipitate was further analyzed by HSQC and ${ }^{31} \mathrm{P}$ NMR spectroscopy (Figure 14 and Figure 15). Regarding the aliphatic oxygenated region, spectra indicated that carbohydrates present in initial Kraft, SEL and PEL lignins despaired since the reaction temperature was reached. Additionally, for Kraft and SEL lignins, correlations attributed to cinnamic alcohols $\left(D_{\gamma}: \delta_{H} / \delta_{c}-4,12 / 62 \mathrm{ppm}\right)$ disappeared as well. Inter-units bonds, i.e. $\beta-0-4\left(A / A^{\prime} / A^{\prime \prime}\right), \beta-\beta$ (B) and $\beta-5$ (C) were not affected by heating to reaction temperature under nitrogen atmosphere as correlations appeared unaffected at $t=0$. After that differences were observed in reactivity depending on the nature of lignin. For PEL lignin, correlations corresponding to $\beta-5\left(\mathbf{C}_{\alpha}: \delta_{H} / \delta_{c}-5,49 / 87,6 p p m ; C_{\beta}: \delta_{H} / \delta_{c}-3,47 / 53,96 p p m\right)$ disappeared after 30 min reaction and those corresponding to $\beta-\beta\left(B_{\alpha}: \delta_{H} / \delta_{C}-4,64 / 54,2 p p m ; B_{\beta}: \delta_{H} / \delta_{C}-3,06 / 54,2\right.$ ppm ; $B_{\gamma}: \delta_{H} / \delta_{c}-4,16 / 71,7$ ppm) disappeared after $1 \mathrm{~h}$. For Kraft lignin, these correlations stayed observable up to $1 \mathrm{~h}$ reaction, time at which they decreased and disappeared. For SEL lignin all correlated remained observable while with lower intensity after $1 \mathrm{~h}$ reaction. Regarding the aromatic region it was observed that correlation corresponding to ferylates (FA), coumarylates ( $\boldsymbol{p}$-CA) and 
cinnaldehydes $(F)$ were absent after reaching reaction temperature under nitrogen atmosphere. FOr Kraft lignin, correlations attributed to olefin moieties disappeared as well. For all lignins, intensity of signals corresponding to aromatics decreased. Thus, correlations attributed to $\mathrm{H}$ units $\mathrm{H}_{2,6}: \delta_{\mathrm{H}} / \delta_{\mathrm{C}}$ 7,09/129.2 ppm) disappeared after 15 min reaction time. At the same time, correlations characteristic of guaiacyl $G$ and syringyl $S$ units $\left(\mathbf{G}_{2}^{\prime}: \delta_{H} / \delta_{C}-7,09 / 129.2 \mathrm{ppm} ; \mathbf{S}_{2}{ }_{2}: \delta_{H} / \delta_{\mathrm{C}}-7,09 / 129.2 \mathrm{ppm}\right)$ first increase in intensity before deceasing slowly that is corroborated by observations made in FTIR spectroscopy. These modifications were accompanied by apparition of correlation characteristic of conjugated olefins $\left(\delta_{\mathrm{H}}: 6,82-7,64 \mathrm{ppm} / \delta_{\mathrm{C}}: 122,7-129,5 \mathrm{ppm}\right)$.
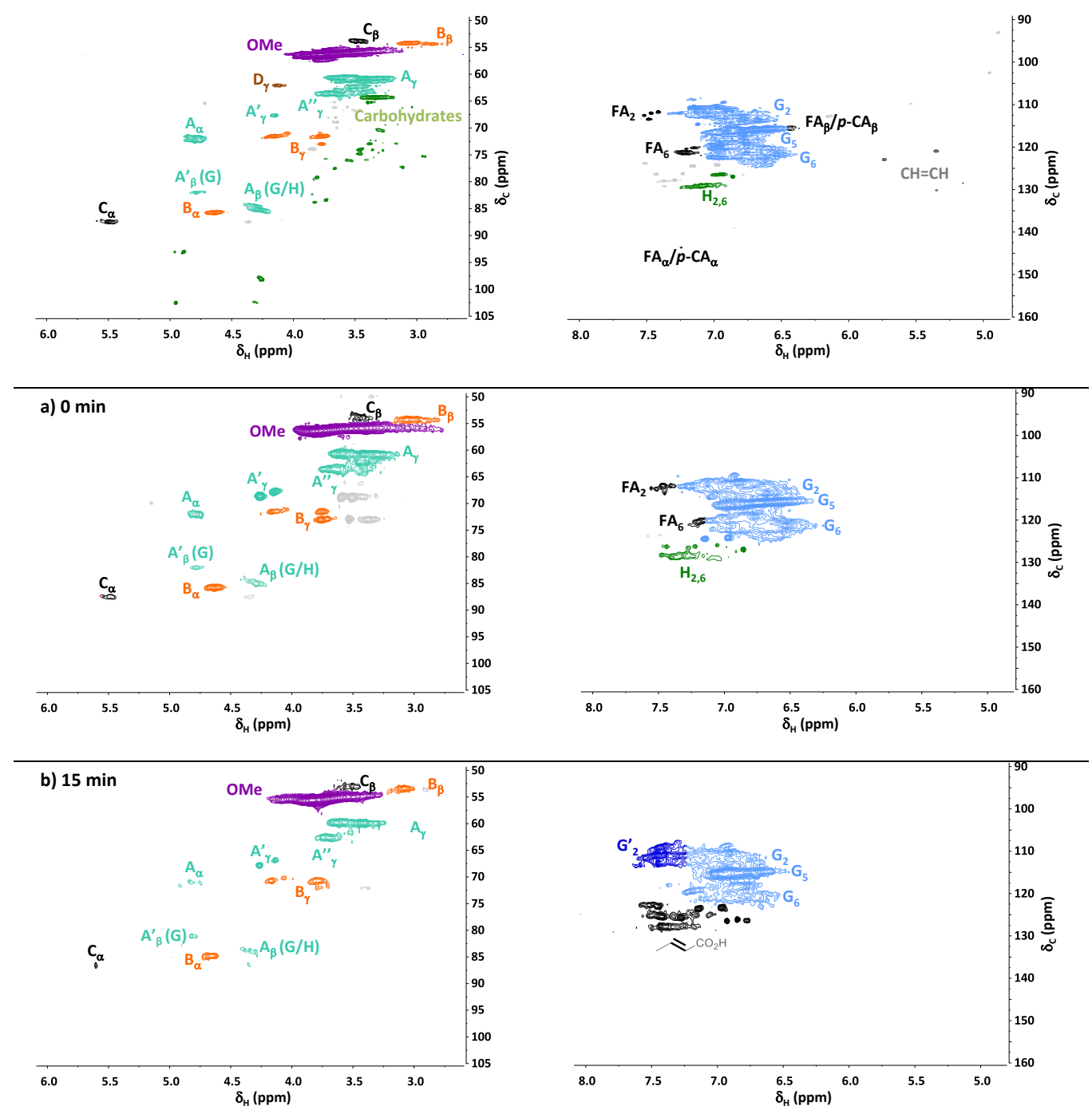

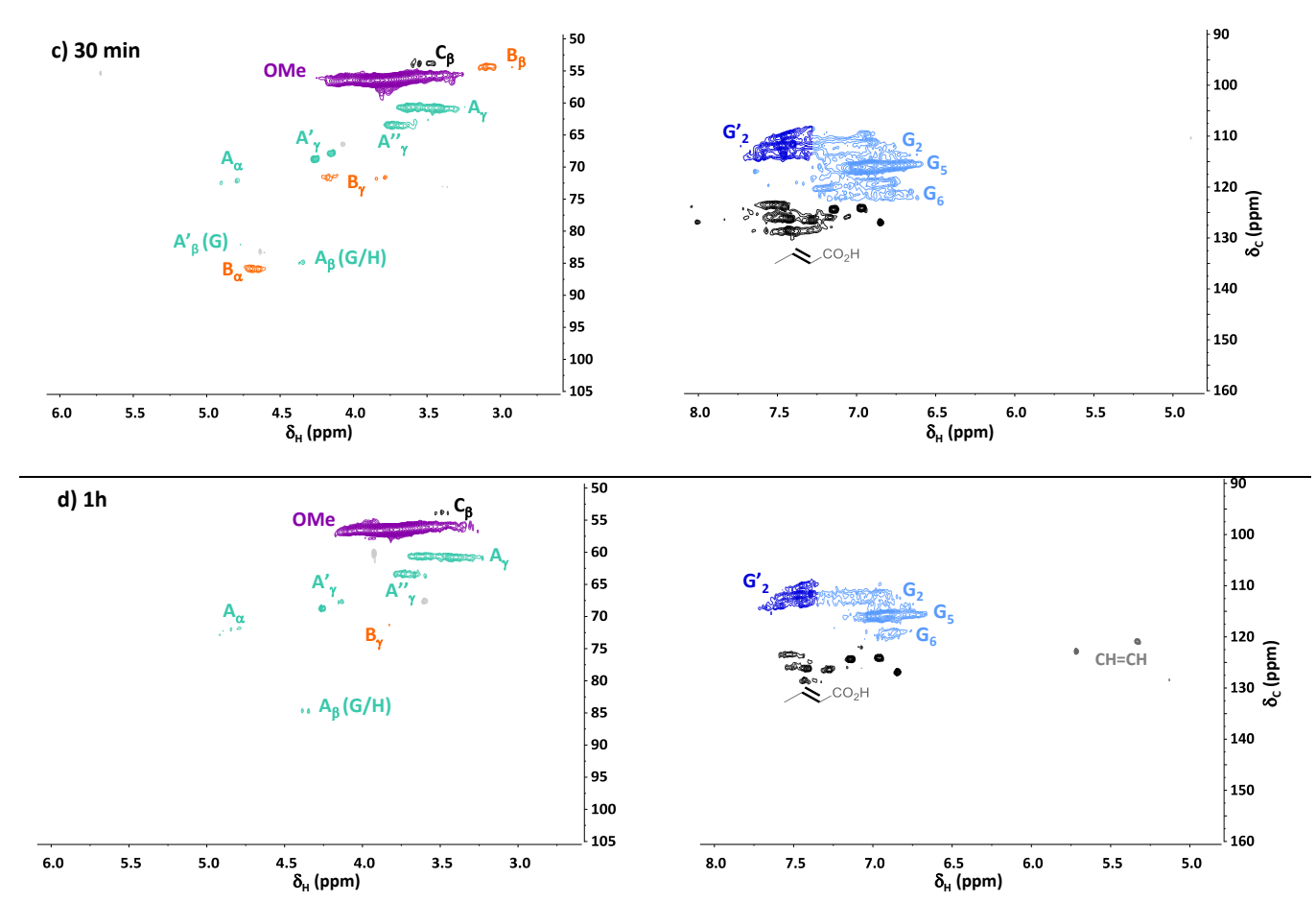

Figure 14: HSQC NMR spectra of Kraft lignin (Oxygenated aliphatic region [links] and aromatic region [right]) versus the time over $1 \mathrm{~h}$ reaction time with key structural identification (see Supporting Information for HSQC spectra versus the time for other lignins). Conditions: $150^{\circ} \mathrm{C}, \mathrm{P}_{\text {air }}: 20 \mathrm{bar}, \mathrm{C}_{\text {lignin }}$ : $5 \mathrm{~g} / \mathrm{L}, \mathrm{C}_{\mathrm{NaOH}}: 10 \mathrm{~g} / \mathrm{L}, 1500 \mathrm{rpm}$.

${ }^{31} \mathrm{P}$ NMR spectroscopy was used to quantify remaining $\mathrm{OH}$ groups in precipitate after phosphitylation, by the nature of their functionality, as a function of the reaction time for the Kraft, SEL and PEL lignins. Data are collected in figure 15. For all lignins it was observed that heating the reaction under nitrogen atmosphere produced a decrease of $\mathrm{OH}$ content. Aliphatic $\mathrm{OH}$ were particularly affected: decrease of $0.5 U_{0}$ for Kraft, $1.1 U_{0}$ for SEL and 1.2 U PEL lignin. Organosolv SEL and PEL lignins exhibited also a decrease in condensed and syringyl OH: $0.4 \mathrm{U}_{\mathrm{O}}$ (SEL) and 0.6 $\mathrm{U}_{\mathrm{O}}$ (PEL). Kraft lignin did not showed such a behavior. Additionally, for all lignins, an increase of the carboxylic $\mathrm{OH}$ content was observed: $0.1 \mathrm{U}_{0}$, $0.2 U_{0}$ and $0.3 U_{O}$ for Kraft, SEL and PEL lignins resp. Once reaction temperature was reached and the reactor pressurized under air, decrease of other $\mathrm{OH}$ type was observed (i.e. corresponding to $\mathrm{H}$, $\mathrm{G}$, les $\mathrm{S}$ condensed units) except for carboxylic $\mathrm{OH}$ type that continue to increase over all the time (i.e. ca. +2.1 Uo). Noticeably, for PEL lignin decrease of $\mathrm{OH}$ content occurred mostly within 15 min time (i.e. $0.5 U_{0}$ for G-units; $-1.7 U_{0}$ for $S$ and condensed units) while for the other lignins the decrease occurred mostly over 1 hour. These data are supported by some of the observations made by FTIR spectroscopy (i.e. for example, decrease of the band attributed to primary alcohols). 

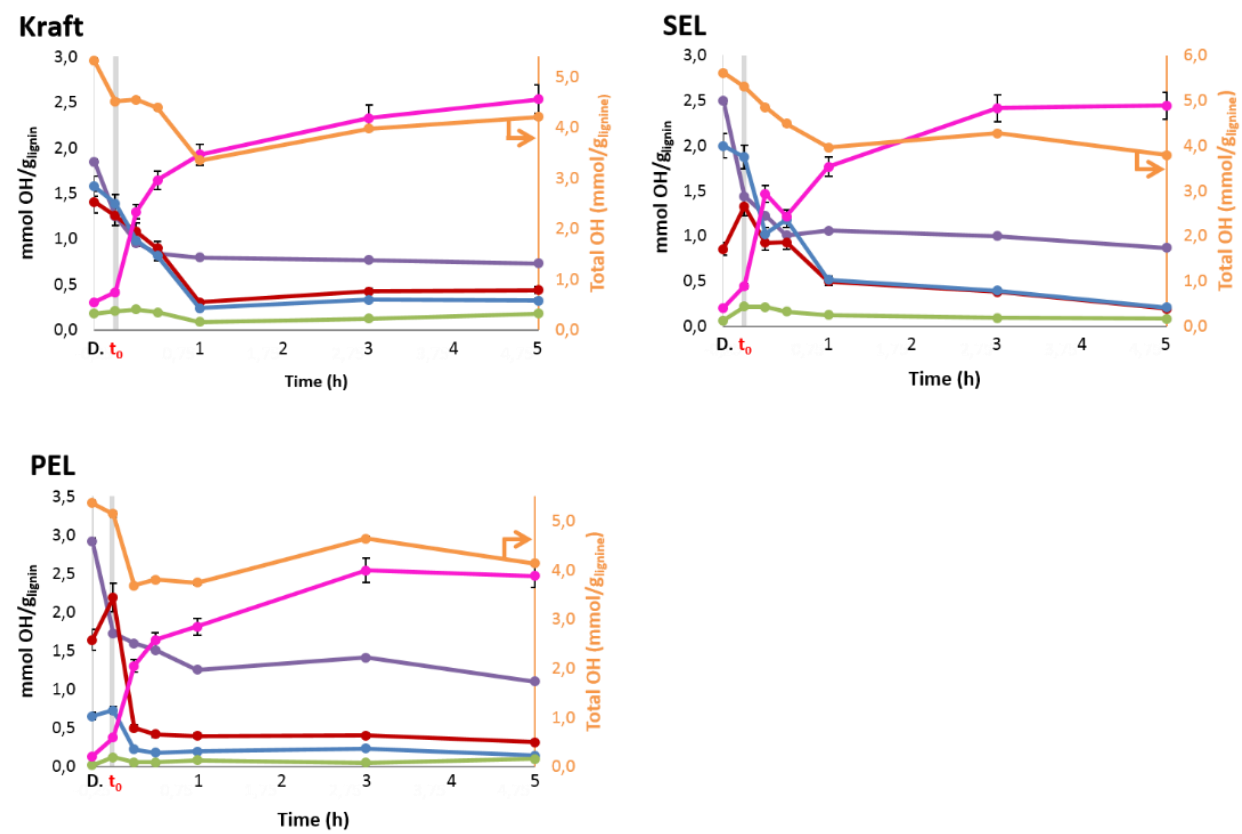

Figure 15: Data issued from ${ }^{31} \mathrm{P}$ NMR spectra for Kraft, SEL and PEL lignins versus the time over $5 \mathrm{~h}$ reaction time. Conditions: $150^{\circ} \mathrm{C}, \mathrm{P}_{\text {air }}: 20$ bar, $\mathrm{Clignin}_{1}: 5 \mathrm{~g} / \mathrm{L}, \mathrm{C}_{\mathrm{NaOH}}: 10 \mathrm{~g} / \mathrm{L}, 1500 \mathrm{rpm}$. Legend: $\mathrm{OH}_{\text {aliphatic, }}$

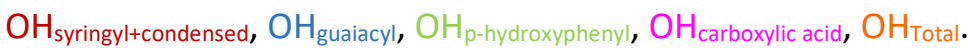

\section{Summary and reflection regarding possible mechanism}

During these works, we demonstrated that the nature of media played a crucial role on lignin reactivity. Thus under acidic or neural pH, no reaction occurred on lignins whereas under basic condition lignin transformations were observed. This was correlated to oxygen consumption: under acidic condition 8 mmol oxygen were consumed that was attributed to dissolution in the reaction media; under neutral conditions $13 \mathrm{mmol}$ were consumed that was correlated to carbohydrate degradation (in addition to dissolution). Under basic conditions, $25 \mathrm{mmol}$ oxygen were consumed that corresponds to the cumulus of oxygen dissolution, carbohydrate degradation on lignin transformation. In this approach, it was pointed out that the base, in addition to allowing the dissolution of lignins, played also major role in their transformation through a base catalyzed process. According to the reports of Tarabanko at al. ${ }^{117}$, 118 and Wallick et al. ${ }^{157}$ we proposed routes to account for the formation of the main aromatic compounds, i.e. vanillin and acetovanillone starting by deprotonation of phenolic moieties by hydroxides (Scheme 1). While in this mechanism oxygen did not play a role, however, it is involved in direct oxidation of lignin biopolymer to afford reactive sites (i.e. guaiacyl moieties...) involved then in the formation of observed aromatic compounds; it is also involved in over oxidation of the aromatic compounds formed to give diacids (i.e. succinic acid, muconic acid...) explaining why at low base loading the conversion of lignins stopped due neutralization of hydroxide ions. 


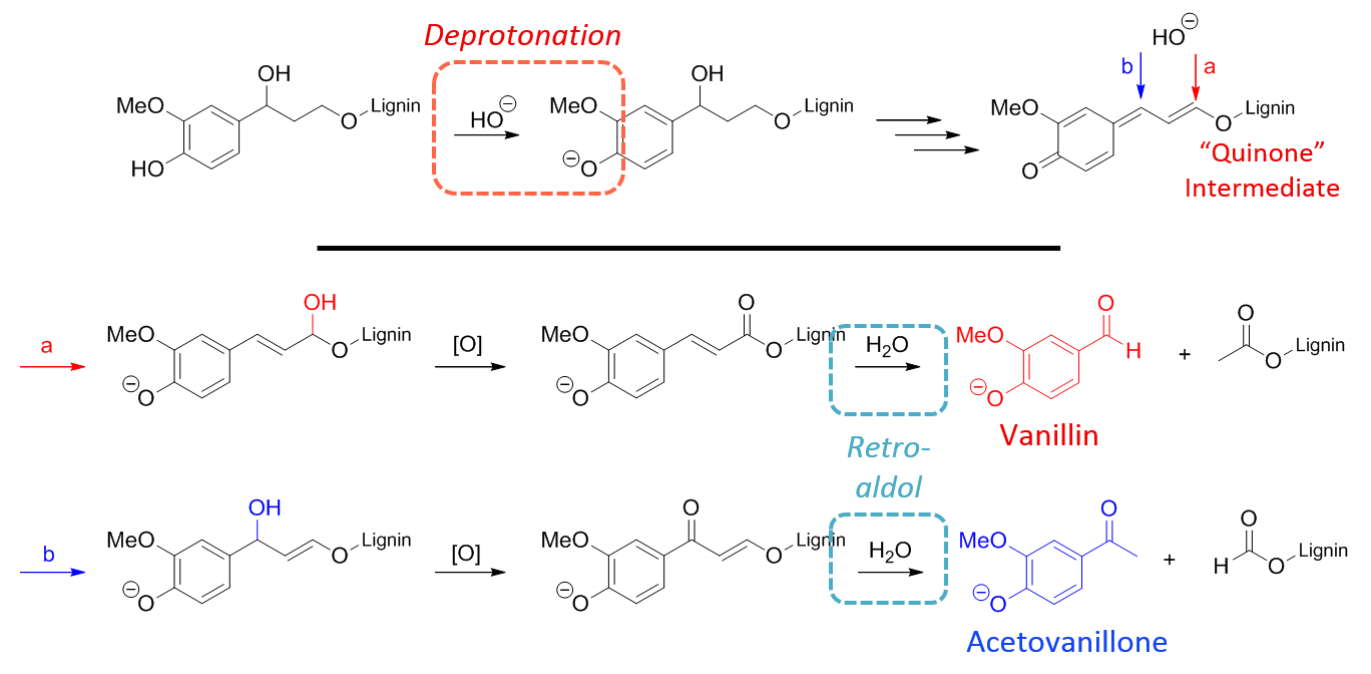

Scheme 1: proposed formation of vanillin and acetovanillone when treating lignins under oxidative atmosphere under basic conditions.

The data obtained by studying the depolymerization of various lignins under oxidative atmosphere showed that lignin oxidation really started under oxidative atmosphere whereas residual carbohydrates and ferulic and cinnamic compounds initially present in some lignins were decomposed under nitrogen atmosphere given their reactivity toward highly basic media. Lignin oxidation by air was, under our reaction conditions, initially characterized by the formation of guaiacyl and syringyl sub-units, delivering thus functionality allowing the production of aromatic compounds according Scheme 1. At the same time, inter-units $\beta-\beta$ (B), $\beta-5$ (C) and $\beta-O-4$ ( $A$ ) bonds disappeared at various rate depending on lignin origin; however, without any selectivity. This could indicate that, under our conditions, lignin was depolymerized by reaction with accessible phenolic function like those encountered at chain ends, rather than by selective cleavage of some inter-units bonds leading thus to the formation of oligomeric structures more sensitive to depolymerization.

\section{Conclusions}

In this contribution we evaluated the depolymerization of lignins varying by their botanic origin (i.e.: Softwoods, Hardwoods, annual plants) and their extraction methods (i.e.: Kraft, Soda, Organosolv) under oxidative conditions without using catalysts taking advantage of the highly basic media (reaction conditions: $150^{\circ} \mathrm{C}, \mathrm{P}_{\text {air: }} 20$ bar, $\left.\mathrm{C}_{\text {lignin: }} \mathrm{5g} / \mathrm{L}, \mathrm{C}_{\mathrm{NaOH}}: 10 \mathrm{~g} / \mathrm{L}, 1500 \mathrm{rpm}\right)$. According previous reports, we showed that the use of a base, here $\mathrm{NaOH}$, in relative high concentration was necessary to observed lignin depolymerization as acid or neutral conditions prevented reaction to occur. Additionally, we showed that under neutral atmosphere, lignin was not affected whereas remaining carbohydrates 
were decomposed upon heating. Results showed that softwood lignins (i.e.: Kraft (G) and SEL (G)) were less reactive under our reaction conditions than hardwood (i.e.: PEL $(G+S)$ or annual plants (i.e.: P1000 $(\mathrm{G}+\mathrm{S})$ and Formic $(\mathrm{G}+\mathrm{S})$ ) probably due to condensation side reactions during either extraction or oxidative treatment at 5 position of guaiacyl units. This interpretation was supported by data obtained from ${ }^{31} \mathrm{P}$ NMR analyses. However, data showed that the highest yields in aromatic compounds were achieved with Kraft (4.1\%), SEL (6.1\%) and PEL (5.3\%) lignins, exhibiting that ethanol lignins presented interested behavior in such applications. Nevertheless, data indicated as well that syringyl units containing lignins, while easier to depolymerize did not led to high yields in aromatics due to over oxidation reactions of the products formed as attested by the general low mass balance and formation of volatile compounds in gas phase.

Spectroscopic analyses encouraged us to propose that depolymerization of lignins, at least under our reaction conditions, occurred from accessible phenolic groups that are generally encountered at chain ends. This proposal agree with the work reported by Tarabanko et al. Spectroscopic data supported also such interpretation, particularly the facts that no selectivity was observed in the cleavage of some inter-units bonds and observations made in FTIR spectroscopy related to a light increase of the guaiacyl units before decreasing as theses will offer additional sites for depolymerization reaction. Additionally, we observed that Organosolv lignins, reputed to have lower chain length, led to higher rate of depolymerization. At short reaction times, they gave the highest yields in aromatic compounds. This contrast with some reports in the literature that proposed first the cleavage of some bonds to depolymerize lignins to lower oligomers before transforming further the biomasse to monomeric compounds.

\section{References}

1. Rinaldi, R.; Jastrzebski, R.; Clough, M. T.; Ralph, J.; Kennema, M.; Bruijnincx, P. C. A.; Weckhuysen, B. M. Angew. Chem. Int. Ed. 2016, 55, 8164-8215.

2. Zhang, Z.; Song, J.; Han, B. Chem. Rev. 2017, 117, 6834-6880.

3. Donald, D., Overview. In Lignin and Lignans: Advances in Chemistry, Heitner, C.; Dimmel, D. R.; Schmidt, J. A., Eds. CRC Press: 2010; pp 1-10.

4. Lapierre, C., Determining Lignin Structure by Chemical Degradations. In Lignin and Lignans: Advances in Chemistry, Heitner, C.; Dimmel, D. R.; Schmidt, J. A., Eds. CRC Press: 2010; pp 49-102.

5. Constant, S.; Wienk, H. L. J.; Frissen, A. E.; de Peinder, P.; Boelens, R.; van Es, D. S.; Grisel, R. J. H.; Weckhuysen, B. M.; Huijgen, W. J. J.; Gosselink, R. J. A.; Bruijnincx, P. C. A. Green Chem. 2016, 18, 2651-2665.

6. Deuss, P. J.; Barta, K. Coord. Chem. Rev. 2016, 306, Part 2, 510-532.

7. de Menezes, F. F.; Rencoret, J.; Nakanishi, S. C.; Nascimento, V. M.; Silva, V. F. N.; Gutiérrez, A.; del Río, J. C.; de Moraes Rocha, G. J. ACS Sus. Chem. Engineer. 2017, 5, 5702-5712.

8. Zakzeski, J.; Bruijnincx, P. C. A.; Jongerius, A. L.; Weckhuysen, B. M. Chem. Rev. 2010, 110, $3552-$ 3599. 
9. Zakzeski, J.; Jongerius, A. L.; Bruijnincx, P. C.; Weckhuysen, B. M. ChemSusChem 2012, 5, 1602-

9.

10. Xu, C.; Arancon, R. A. D.; Labidi, J.; Luque, R. Chem. Soc. Rev. 2014, 43, 7485-7500.

11. Dai, J.; Patti, A. F.; Saito, K. Tetrahedron Lett. 2016, 57, 4945-4951.

12. Galkin, M. V.; Samec, J. S. M. Chem. Sus. Chem. 2016, 9, 1544-1558.

13. Gillet, S.; Aguedo, M.; Petitjean, L.; Morais, A. R. C.; da Costa Lopes, A. M.; Lukasik, R. M.; Anastas, P. T. Green Chem. 2017, 19, 4200-4233.

14. Kruger, J. S.; Cleveland, N. S.; Zhang, S.; Katahira, R.; Black, B. A.; Chupka, G. M.; Lammens, T.; Hamilton, P. G.; Biddy, M. J.; Beckham, G. T. ACS Catalysis 2016, 6, 1316-1328.

15. Jastrzebski, R.; Constant, S.; Lancefield, C. S.; Westwood, N. J.; Weckhuysen, B. M.; Bruijnincx, P. C. A. ChemSusChem 2016, 9, 2074-2079.

16. Güvenatam, B.; Heeres, E. H. J.; Pidko, E. A.; Hensen, E. J. M. Catal. Today 2016, 269, 9-20.

17. Zhang, G.; Wen, Y.; Liu, Z.; Zhang, S.; Li, G. Appl. Catal. A: Gen. 2017, 542, 1-9.

18. Rodriguez, A.; Salvachúa, D.; Katahira, R.; Black, B. A.; Cleveland, N. S.; Reed, M.; Smith, H.; Baidoo, E. E. K.; Keasling, J. D.; Simmons, B. A.; Beckham, G. T.; Gladden, J. M. ACS Sus. Chem. Engineer. 2017, 5, 8171-8180.

19. Thierry, M.; Majira, A.; Pégot, B.; Cezard, L.; Bourdreux, F.; Clément, G.; Perreau, F.; BoutetMercey, S.; Diter, P.; Vo-Thanh, G.; Lapierre, C.; Ducrot, P.-H.; Magnier, E.; Baumberger, S.; Cottyn, B. ChemSusChem 2018, 11, 439-448.

20. Singh, S. K.; Banerjee, S.; Vanka, K.; Dhepe, P. L. Catal. Today 2018, 309, 98-108.

21. Kuznetsov, B. N.; Sudakova, I. G.; Garyntseva, N. V.; Djakovitch, L.; Pinel, C. React. Kinet., Mech. Catal. 2013, 110, 271-280.

22. Kuznetsova, B. N.; Garyntseva, N. V.; Levdansky, A. V.; Djakovitch, L.; Pinel, C. J. Sib. Fed. Univ., Chem. 2014, 7, 316-325.

23. Sharypov, V. L.; Kuznetsov, B. N.; Yakovlev, V. A.; Beregovtsova, N. G.; Baryshnikov, S. V.; Djakovitch, L.; Pinel, C. J. Sib. Fed. Univ., Chem. 2015, 3, 465-475.

24. Kuznetsov, B. N.; Sudakova, I. G.; Garyntseva, N. V.; Djakovitch, L.; Pinel, C. Reac Kinet Mech Cat 2016, 1-14.

25. Cattelan, L.; Yuen, A. K. L.; Lui, M. Y.; Masters, A. F.; Selva, M.; Perosa, A.; Maschmeyer, T. Chem. Cat. Chem. 2017, 9, 2717-2726.

26. Kuznetsov, B. N.; Chesnokov, N. V.; Sudakova, I. G.; Garyntseva, N. V.; Kuznetsova, S. A.; Malyar, Y. N.; Yakovlev, V. A.; Djakovitch, L. Catal. Today 2018, 309, 18-30.

27. Kuznetsov, B. N.; Chesnokov, N. V.; Garyntseva, N. V.; Sudakova, I. G.; Pestunov, A. V.; Djakovitch, L.; Pinel, C. Kin. Catal. 2018, 59, 48-57.

28. Kuznetsov, B. N.; Sharypov, V. I.; Beregovtsova, N. G.; Baryshnikov, S. V.; Pestunov, A. V.; Vosmerikov, A. V.; Djakovitch, L. J. Anal. Appl. Pyrol. 2018, 132, 237-244.

29. Løhre, C.; Laugerud, G.-A. A.; Huijgen, W. J. J.; Barth, T. ACS Sus. Chem. Engineer. 2018, 6, $3102-$ 3112.

30. Huang, X.; Koranyi, T. I.; Boot, M. D.; Hensen, E. J. M. Green Chem. 2015, 17, 4941-4950.

31. Liu, W.-J.; Jiang, H.; Yu, H.-Q. Green Chem. 2015, 17, 4888-4907.

32. Kozliak, E. I.; Kubátová, A.; Artemyeva, A. A.; Nagel, E.; Zhang, C.; Rajappagowda, R. B.; Smirnova, A. L. ACS Sus. Chem. Engineer. 2016, 4, 5106-5122.

33. Cronin, D. J.; Dunn, K.; Zhang, X.; Doherty, W. O. S. ACS Sus. Chem. Engineer. 2017, 5, 1169511705.

34. Lui, M. Y.; Chan, B.; Yuen, A. K. L.; Masters, A. F.; Montoya, A.; Maschmeyer, T. ChemSusChem 2017, 10, 2140-2144.

35. Miyata, Y.; Sagata, K.; Hirose, M.; Yamazaki, Y.; Nishimura, A.; Okuda, N.; Arita, Y.; Hirano, Y.; Kita, Y. ACS Sus. Chem. Engineer. 2017, 5, 3562-3569.

36. Egesa, D.; Chuck, C. J.; Plucinski, P. ACS Sus. Chem. Engineer. 2018, 6, 991-999.

37. Custodis, V. B. F.; Karakoulia, S. A.; Triantafyllidis, K. S.; van Bokhoven, J. A. Chem. Sus. Chem. 2016, 9, 1134-1145.

38. Zhou, S.; Xue, Y.; Sharma, A.; Bai, X. ACS Sus. Chem. Engineer. 2016, 4, 6608-6617. 
39. Humbird, D.; Trendewicz, A.; Braun, R.; Dutta, A. ACS Sus. Chem. Engineer. 2017, 5, 2463-2470.

40. Lee, J. E.; Park, H. C.; Choi, H. S. ACS Sus. Chem. Engineer. 2017, 5, 2196-2204.

41. Lou, R.; Lyu, G.; Wu, S.; Zhang, B.; Zhao, H.; Lucia, L. A. ACS Sus. Chem. Engineer. 2018, 6, 430-

437.

42. Opris, C.; Cojocaru, B.; Gheorghe, N.; Tudorache, M.; Coman, S. M.; Parvulescu, V. I.; Duraki, B.; Krumeich, F.; van Bokhoven, J. A. J. Catal. 2016, 339, 209-227.

43. Chen, J.; Lu, F.; Si, X.; Nie, X.; Chen, J.; Lu, R.; Xu, J. Chem. Sus. Chem. 2016, 9, 3353-3360.

44. Barrett, J. A.; Gao, Y.; Bernt, C. M.; Chui, M.; Tran, A. T.; Foston, M. B.; Ford, P. C. ACS Sus. Chem. Engineer. 2016, 4, 6877-6886.

45. Guo, H.; Zhang, B.; Qi, Z.; Li, C.; Ji, J.; Dai, T.; Wang, A.; Zhang, T. Chem. Sus. Chem. 2017, 10, 523-532.

46. Qi, S.-C.; Hayashi, J.-i.; Kudo, S.; Zhang, L. Green Chem. 2017, 19, 2636-2645.

47. Zhai, Y.; Li, C.; Xu, G.; Ma, Y.; Liu, X.; Zhang, Y. Green Chem. 2017, 19, 1895-1903.

48. Kumaniaev, I.; Subbotina, E.; Savmarker, J.; Larhed, M.; Galkin, M. V.; Samec, J. S. M. Green Chem. 2017, 19, 5767-5771.

49. Kärkäs, M. D. ChemSusChem 2017, 10, 2111-2115.

50. Xiao, L.-P.; Wang, S.; Li, H.; Li, Z.; Shi, Z.-J.; Xiao, L.; Sun, R.-C.; Fang, Y.; Song, G. ACS Catalysis 2017, 7535-7542.

51. Dong, L.; Yin, L.-L.; Xia, Q.; Liu, X.; Gong, X.-Q.; Wang, Y. Cat. Sci. Tech. 2018, 8, 735-745.

52. Ouyang, X.; Huang, X.; Hendriks, B. M. S.; Boot, M. D.; Hensen, E. J. M. Green Chem. 2018, 20, 2308-2319.

53. Anderson, E. M.; Stone, M. L.; Hülsey, M. J.; Beckham, G. T.; Román-Leshkov, Y. ACS Sus. Chem. Engineer. 2018.

54. Lan, W.; Amiri, M. T.; Hunston, C. M.; Luterbacher, J. S. Angew. Chem. Int. Ed. 2018, 57, 13561360.

55. Regmi, Y. N.; Mann, J. K.; McBride, J. R.; Tao, J.; Barnes, C. E.; Labbé, N.; Chmely, S. C. Catal. Today 2018, 302, 190-195.

56. Luo, H.; Klein, I. M.; Jiang, Y.; Zhu, H.; Liu, B.; Kenttämaa, H. I.; Abu-Omar, M. M. ACS SusChemEng 2016, 4, 2316-2322.

57. Anderson, E. M.; Katahira, R.; Reed, M.; Resch, M. G.; Karp, E. M.; Beckham, G. T.; RománLeshkov, Y. ACS Sus. Chem. Engineer. 2016, 4, 6940-6950.

58. Huang, X.; Zhu, J.; Korányi, T. I.; Boot, M. D.; Hensen, E. J. M. Chem. Sus. Chem. 2016, 9, 32623267.

59. Luo, H.; Abu-Omar, M. M. Green Chem. 2018, 20, 745-753.

60. Monsigny, L.; Feghali, E.; Berthet, J.-C.; Cantat, T. Green Chem. 2018, 20, 1981-1986.

61. Chen, L.; Xin, J.; Ni, L.; Dong, H.; Yan, D.; Lu, X.; Zhang, S. Green Chem. 2016, 18, 2341-2352.

62. Wang, H.; Ben, H.; Ruan, H.; Zhang, L.; Pu, Y.; Feng, M.; Ragauskas, A. J.; Yang, B. ACS Sus. Chem. Engineer. 2017, 5, 1824-1830.

63. Agarwal, S.; Chowdari, R. K.; Hita, I.; Heeres, H. J. ACS Sus. Chem. Engineer. 2017, 5, 2668-2678.

64. Taraban'ko, V. E.; Koropatchinskaya, N. V.; Kudryashev, A. V.; Kuznetsov, B. N. Russ. Chem. Bull. 1995, 44, 367-371.

65. Taraban'ko, V. E.; Ivanchenko, N. M.; Koropachinskaya, N. V.; Kuznetsov, B. N. Chem. Sus. Develop. 1996, 4, 391-402.

66. Lange, H.; Decina, S.; Crestini, C. Eur. Polym. J. 2013, 49, 1151-1173.

67. Ma, R.; Xu, Y.; Zhang, X. ChemSusChem 2015, 8, 24-51.

68. Behling, R.; Valange, S.; Chatel, G. Green Chem. 2016, 18, 1839-1854.

69. Ma, R.; Guo, M.; Zhang, X. Catal. Today 2018, 302, 50-60.

70. Vardon, D. R.; Franden, M. A.; Johnson, C. W.; Karp, E. M.; Guarnieri, M. T.; Linger, J. G.; Salm, M. J.; Strathmann, T. J.; Beckham, G. T. Energy Environ. Sci. 2015, 8, 617-628.

71. Salvachua, D.; Katahira, R.; Cleveland, N. S.; Khanna, P.; Resch, M. G.; Black, B. A.; Purvine, S. O.; Zink, E. M.; Prieto, A.; Martinez, M. J.; Martinez, A. T.; Simmons, B. A.; Gladden, J. M.; Beckham, G. T. Green Chem. 2016, 18, 6046-6062. 
72. Lancefield, C. S.; Rashid, G. M. M.; Bouxin, F.; Wasak, A.; Tu, W.-C.; Hallett, J.; Zein, S.; Rodríguez, J.; Jackson, S. D.; Westwood, N. J.; Bugg, T. D. H. ACS Sus. Chem. Engineer. 2016, 4, 69216930.

73. Xie, S.; Sun, Q.; Pu, Y.; Lin, F.; Sun, S.; Wang, X.; Ragauskas, A. J.; Yuan, J. S. ACS Sus. Chem. Engineer. 2017, 5, 2215-2223.

74. Ni, J.; Gao, Y.-Y.; Tao, F.; Liu, H.-Y.; Xu, P. Angew. Chem. Int. Ed. 2018, 57, 1214-1217.

75. Si, M.; Yan, X.; Liu, M.; Shi, M.; Wang, Z.; Wang, S.; Zhang, J.; Gao, C.; Chai, L.; Shi, Y. ACS Sus. Chem. Engineer. 2018, 6, 7969-7978.

76. Tarabanko, V. E.; Kaygorodov, K. L.; Skiba, E. A.; Tarabanko, N.; Chelbina, Y. V.; Baybakova, O. V.; Kuznetsov, B. N.; Djakovitch, L. J. Wood Chem. Techn. 2017, 37, 43-51.

77. Crestini, C.; D'Auria, M. Tetrahedron 1997, 53, 7877-7888.

78. Crestini, C.; Caponi, M. C.; Argyropoulos, D. S.; Saladino, R. Bioorg. Med. Chem. 2006, 14, 52925302.

79. Crestini, C.; Crucianelli, M.; Orlandi, M.; Saladino, R. Catal. Today 2010, 156, 8-22.

80. Ma, R.; Guo, M.; Zhang, X. ChemSusChem 2014, 7, 412-415.

81. François, N.; Ludivine, J. G.; Catherine, G. H.; Micheline, D.; Bruno, A. Eur. J. Org. Chem. 2014, 2014, 781-787.

82. Alunga, K. R.; Ye, Y.-Y.; Li, S.-R.; Wang, D.; Liu, Y.-Q. Cat. Sci. Tech. 2015, 5, 3746-3753.

83. Hanson, S. K.; Baker, R. T. Acc. Chem. Res. 2015, 48, 2037-2048.

84. Ma, Y.; Du, Z.; Liu, J.; Xia, F.; Xu, J. Green Chem. 2015, 17, 4968-4973.

85. Díaz-Urrutia, C.; Sedai, B.; Leckett, K. C.; Baker, R. T.; Hanson, S. K. ACS Sus. Chem. Engineer. 2016, 4, 6244-6251.

86. Parker, H. J.; Chuck, C. J.; Woodman, T.; Jones, M. D. Catal. Today 2016, 269, 40-47.

87. Rodrigues Pinto, P. C.; Borges da Silva, E. A.; Rodrigues, A. E., Lignin as Source of Fine Chemicals: Vanillin and Syringaldehyde. In Biomass Conversion, Baskar, C.; Baskar, S.; Dhillon, R. S., Eds. Springer Berlin Heidelberg: 2012; pp 381-420.

88. Mottweiler, J.; Rinesch, T.; Besson, C.; Buendia, J.; Bolm, C. Green Chem. 2015, 17, 5001-5008.

89. Voitl, T.; von Rohr, P. R. ChemSusChem 2008, 1, 763-769.

90. Voitl, T.; Rohr, P. R. v. Indus. Engineer. Chem. Res. 2010, 49, 520-525.

91. De Gregorio, G. F.; Prado, R.; Vriamont, C.; Erdocia, X.; Labidi, J.; Hallett, J. P.; Welton, T. ACS Sus. Chem. Engineer. 2016, 4, 6031-6036.

92. Prado, R.; Erdocia, X.; De Gregorio, G. F.; Labidi, J.; Welton, T. ACS Sus. Chem. Engineer. 2016, 4, 5277-5288.

93. Vidal, J.-P., Vanillin. In Kirk-Othmer Encyclopedia of Chemical Technology, John Wiley \& Sons, Inc.: 2000.

94. Rødsrud, G.; Lersch, M.; Sjöde, A. Biomass and Bioenergy 2012, 46, 46-59.

95. Bjørsvik, H.-R.; Minisci, F. Org. Proc. Res. Develop. 1999, 3, 330-340.

96. Sagues, W. J.; Bao, H.; Nemenyi, J. L.; Tong, Z. ACS Sus. Chem. Engineer. 2018, 6, 4958-4965.

97. Rahimi, A.; Azarpira, A.; Kim, H.; Ralph, J.; Stahl, S. S. J. Am. Chem. Soc. 2013, 135, 6415-6418.

98. Rahimi, A.; Ulbrich, A.; Coon, J. J.; Stahl, S. S. Nature 2014, 515, 249-252.

99. Deuss, P. J.; Scott, M.; Tran, F.; Westwood, N. J.; de Vries, J. G.; Barta, K. J. Am. Chem. Soc. 2015, $137,7456-7467$.

100. Crestini, C.; Pastorini, A.; Tagliatesta, P. Eur. J. Inorg. Chem. 2004, 2004, 4477-4483.

101. Crestini, C.; Pastorini, A.; Tagliatesta, P. J. Mol Catal. A: Chem. 2004, 208, 195-202.

102. Mottweiler, J.; Puche, M.; Räuber, C.; Schmidt, T.; Concepción, P.; Corma, A.; Bolm, C. ChemSusChem 2015, 8, 2106-2113.

103. Deng, H.; Lin, L.; Sun, Y.; Pang, C.; Zhuang, J.; Ouyang, P.; Li, Z.; Liu, S. Catal. Lett. 2008, 126, 106-111.

104. Zhang, J.; Deng, H.; Lin, L. Molecules 2009, 14, 2747-2757.

105. Deng, H.; Lin, L.; Liu, S. Energy \& Fuels 2010, 24, 4797-4802.

106. Sales, F. G.; Maranhão, L. C. A.; Filho, N. M. L.; Abreu, C. A. M. Chem. Eng. Sci. 2007, 62, 53865391. 
107. Sales, F. G.; Maranhão, L. C. A.; Lima Filho, N. M.; Abreu, C. A. M. Ind. Eng. Chem. Res. 2006, 45, 6627-6631.

108. Villar, J. C.; Caperos, A.; García-Ochoa, F. Wood Sci. Technol. 2001, 35, 245-255.

109. Qu, C.; Kaneko, M.; Kashimura, K.; Tanaka, K.; Ozawa, S.; Watanabe, T. ACS Sus. Chem. Engineer. 2017, 5, 11551-11557.

110. Vishtal, A.; Kraslawski, A. BioRes. 2011, 6, 3547 - 3568.

111. Katahira, R.; Kamitakahara, H.; Takano, T.; Nakatsubo, F. J. Wood Sci. 2006, 52, 255-260.

112. Chatel, G.; Rogers, R. D. ACS Sus. Chem. Engineer. 2014, 2, 322-339.

113. Rodrigues Pinto, P. C.; Borges da Silva, E. A.; Rodrigues, A. E. Ind. Eng. Chem. Res. 2011, 50, 741-748.

114. Rodrigues Pinto, P. C.; Costa, C. E.; Rodrigues, A. E. Ind. Eng. Chem. Res. 2013, 52, 4421-4428.

115. Pacek, A. W.; Ding, P.; Garrett, M.; Sheldrake, G.; Nienow, A. W. Ind. Eng. Chem. Res. 2013, 52, 8361-8372.

116. Araújo, J. D. P.; Grande, C. A.; Rodrigues, A. E. Catal. Today 2009, 147, Supplement, S330-S335.

117. Tarabanko, V. E.; Fomova, N. A.; Kuznetsov, B. N.; Ivanchenko, N. M.; Kudryashev, A. V. React. Kinet. Catal. Lett. 1995, 55, 161-170.

118. Tarabanko, V. E.; Petukhov, D. V.; Selyutin, G. E. Kinetics and Catalysis 2004, 45, 569-577.

119. Villar, J. C.; Caperos, A.; García-Ochoa, F. Wood Sci. Technol. 2001, 35, 245-255.

120. V.E.Tarabanko; Fomova, N. A.; B.N.Kuznetsov; Ivanchenko, N. M.; A.V.Kudryashev React. Kinet. Catal. Lett. 1995, 55, 161-170.

121. The highly alkaline black liquor was neutralized with $\mathrm{CO} 2$ by bubbling to precipitate lignin. After centrifugation, the recovered solid has a purity of $60 \%$. It was washed by dispersing it in a $2 \% \mathrm{wt} \mathrm{H} 2 \mathrm{SO} 4$ followed by centrifugation. After three purification cycles and drying, a purity of $92 \%$ was achieved.

122. Quesada-Medina, J.; López-Cremades, F. J.; Olivares-Carrillo, P. Bioresour. Technol. 2010, 101, 8252-8260.

123. Wildschut, J.; Smit, A. T.; Reith, J. H.; Huijgen, W. J. J. Bioresour. Technol. 2013, 135, 58-66.

124. Faix, O. Holzforschung 1991, 45, 21-28.

125. Faix, O., Fourier Transform Infrared Spectroscopy. In Methods in Lignin Chemistry, Lin, S.; Dence, C., Eds. Springer Berlin Heidelberg: 1992; pp 233-241.

126. Vázquez, G.; Antorrena, G.; J. González, J.; Freire, S. Holzforschung 1997, 51, 158-166.

127. Pandey, K. K. J. Appl. Polym. Sci. 1999, 71, 1969-1975.

128. Popescu, C.-M.; Popescu, M.-C.; Singurel, G.; Vasile, C.; Argyropoulos, D. S.; Willfor, S. Appl. Spectrosc. 2007, 61, 1168-1177.

129. John, R.; Larry, L. L., NMR of Lignins. In Lignin and Lignans, CRC Press: 2010; pp 137-243.

130. Wen, J.-L.; Sun, S.-L.; Xue, B.-L.; Sun, R.-C. Materials 2013, 6, 359-391.

131. Sette, M.; Lange, H.; Crestini, C. Comput. Struct. Biotechnol. J. 2013, 6, 1-7.

132. Lundquist, K., Proton $\left({ }^{1} \mathrm{H}\right)$ NMR Spectroscopy. In Methods in Lignin Chemistry, Lin, S.; Dence, C., Eds. Springer Berlin Heidelberg: 1992; pp 242-249.

133. Lundquist, K. Nord. Pulp. Pap. Res. J. 1992, 7, 4-9.

134. Robert, D., Carbon-13 Nuclear Magnetic Resonance Spectrometry. In Methods in Lignin Chemistry, Lin, S.; Dence, C., Eds. Springer Berlin Heidelberg: 1992; pp 250-273.

135. Kanitskaya, L. V.; Gogotov, A. F.; Khai, D.; Rokhin, A. V. Russ J Bioorg Chem 2012, 38, 720-725.

136. Argyropoulos, D. S. Res. Chem. Intermed. 1995, 21, 373-395.

137. Granata, A.; Argyropoulos, D. S. J. Agric. Food. Chem. 1995, 43, 1538-1544.

138. Jiang, Z.-H.; Argyropoulos, D. S.; Granata, A. Magn. Reson. Chem. 1995, 33, 375-382.

139. Crestini, C.; Argyropoulos, D. S. J. Agric. Food Chem. 1997, 45, 1212-1219.

140. Pu, Y.; Cao, S.; Ragauskas, A. J. Energy \& Environ. Sci. 2011, 4, 3154-3166.

141. Yuan, T.-Q.; Sun, S.-N.; Xu, F.; Sun, R.-C. J. Agric. Food Chem. 2011, 59, 10604-10614.

142. del Río, J. C.; Rencoret, J.; Prinsen, P.; Martínez, Á. T.; Ralph, J.; Gutiérrez, A. J. Agric. Fodd Chem. 2012, 60, 5922-5935.

143. Zeng, J.; Helms, G. L.; Gao, X.; Chen, S. J. Agric. Food. Chem. 2013, 61, 10848-10857. 
144. del Río, J. C.; Rencoret, J.; Marques, G.; Li, J.; Gellerstedt, G.; Jiménez-Barbero, J.; Martínez, Á. T.; Gutiérrez, A. J. Agric. Food Chem. 2009, 57, 10271-10281.

145. Zhang, A.; Lu, F.; Sun, R.-C.; Ralph, J. J. Agric. Food Chem. 2010, 58, 3446-3450.

146. Sette, M.; Wechselberger, R.; Crestini, C. Chem. Eur. J. 2011, 17, 9529-9535.

147. Huang, X.; Korányi, T. I.; Boot, M. D.; Hensen, E. J. M. Chem. Sus. Chem. 2014, 7, 2276-2288.

148. Wen, J.-L.; Sun, S.-L.; Yuan, T.-Q.; Xu, F.; Sun, R.-C. J. Agric. Food Chem. 2013, 61, 11067-11075.

149. You, T.-T.; Mao, J.-Z.; Yuan, T.-Q.; Wen, J.-L.; Xu, F. J. Agric. Food Chem. 2013, 61, 5361-5370.

150. Delmas, M. Chem. Eng. Technol. 2008, 31, 792-797.

151. Delmas, G.-H.; Benjelloun-Mlayah, B.; Bigot, Y. L.; Delmas, M. J. Appl. Polym. Sci. 2011, 121, 491-501.

152. Mansfield, S. D.; Kim, H.; Lu, F.; Ralph, J. Nat. Protoc. 2012, 7, 1579-1589.

153. It was demonstrated that chemical regime was reached above $1000 \mathrm{rpm}$; we perform therefore all reactions at $1500 \mathrm{rpm}$.

154. Sultanov, V. S.; Wallis, A. F. A. J. Wood. Chem. Technol. 1991, 11, 291-305.

155. Wu, G.; Heitz, M.; Chornet, E. Ind. Eng. Chem. Res. 1994, 33, 718-723.

156. Prado, R.; Brandt, A.; Erdocia, X.; Hallet, J.; Welton, T.; Labidi, J. Green Chem. 2016, 18, 834-

841.

157. Wallick, S. A.; Sarkanen, K. V. Wood Sci.Technol. 1983, 17, 107-116. 